\title{
Tidal forcing on sea-ice drift and deformation in the western Weddell Sea in early austral summer, 2004
}

\author{
Petra Heil $^{\mathrm{a}, *}$, Jennifer K. Hutchings ${ }^{\mathrm{b}}$, Anthony P. Worby ${ }^{\mathrm{a}}$, Milla Johansson ${ }^{\mathrm{c}}$, \\ Jouko Launiainen $^{\mathrm{c}}$, Christian Haas ${ }^{\mathrm{d}, 1}$, William D. Hibler III ${ }^{\mathrm{b}}$ \\ ${ }^{a} A C E C R C \&$ Australian Antarctic Division, University of Tasmania, Hobart, Australia \\ ${ }^{\mathrm{b}}$ International Arctic Research Center, University of Alaska, Fairbanks, USA \\ ${ }^{\mathrm{c}}$ Finnish Institute of Marine Research, Helsinki, Finland \\ ${ }^{\mathrm{d}}$ Alfred Wegener Institute for Polar and Marine Research, Bremerhaven, Germany
}

Accepted 21 December 2007

Available online 2 May 2008

\begin{abstract}
Sea-ice drift and deformation in the western Weddell Sea in early austral summer of 2004 are characterised using in situ data from a meso-scale array of 24 drifting ice buoys. Horizontal GPS-derived position measurements are available from drifting buoys deployed as part of the Ice Station POLarstern [ISPOL] experiment for 26 days during late November and December 2004, at various temporal resolutions and spatial accuracies. These data form the basis for sea-ice velocity and deformation measurements across the meso-scale ISPOL array and at two remote sites. Analysis of the sea-ice velocities reveals coherence for sea-ice drift at separations of less than $70 \mathrm{~km}$; and a correlation length scale of $60 \mathrm{~km}$. Within the limits of the $I S P O L$ array, at larger separations zonal ice drift remains correlated, while meridional ice drift becomes uncorrelated. This together with the east-west gradient in ice velocities indicates the influence of bathymetry, via tidal forcing, on local dynamic processes. Atmospheric forcing also contributes to the sea-ice drift: about $40 \%$ of variability in the sea-ice velocity is explained by changes in wind velocity, which is significantly less than other studies have found for the region during winter. Sea-ice deformation has been derived for the overall array and four sub-arrays. There appeared to be no spatial scale dependency of ice deformation, although considerable spatial variability was observed between sub-arrays. The net divergence of the ISPOL array was in excess of $30 \%$, with the largest contributions to divergence being from the southern section and along the eastern side of the overall ISPOL array. Temporal variability for all deformation parameters is dominated by high-frequency (sub-daily) processes, namely tidal forcing and inertial response. Low-frequency (multiple days) processes, including atmospheric changes, played a secondary role in forcing sea-ice deformation during ISPOL.
\end{abstract}

(C) 2008 Elsevier Ltd. All rights reserved.

Keywords: Sea-ice motion; Sea-ice deformation; High-frequency processes; Ocean tides; Inertial response; Weddell Sea; Antarctica

\section{Introduction}

Observations of sea-ice motion and deformation in the Antarctic are few, particularly from regions that are marked by thick and heavily deformed sea ice, such as the western Weddell Sea. Only a small number of scientific experiments have previously been conducted there. Our knowledge of sea-ice dynamics in that region relies largely

\footnotetext{
${ }^{*}$ Corresponding author. Tel.: + 61362267243 ; fax: +61362267650 .

E-mail address: petra.heil@utas.edu.au (P. Heil).

${ }^{1}$ Present address: Department of Earth \& Atmospheric Sciences, University of Alberta, Edmonton, Canada.
}

on data collected as part of Ice Station Weddell [ISW-1], which was deployed during austral autumn 1992, and provided data at the site of the ice camp as well as from five drifting buoys. In ISW-1 the buoys were spaced to resolve the large-scale (in the order of $150 \mathrm{~km}$ ) sea-ice dynamics (e.g., Geiger et al., 1998a). Further information on sea-ice drift and deformation in the Weddell Sea is available from other buoy deployments (Rowe et al., 1989; Wadhams et al., 1989; Kottmeier et al., 1992; Massom, 1992; Vihma and Launiainen, 1993; Vihma et al., 1996; Uotila et al., 2000).

Previous Weddell Sea expeditions focussed largely on either autumn or winter processes, such as bottom-water formation or surface-flux exchanges (for example, IWS-1 
(e.g., Gordon et al., 1993; Geiger and Drinkwater, 2005); Winter Weddell Gyre Study 1992 (Lemke, 1994)), or on the central and eastern Weddell Sea (Crane and Wadhams, 1996). Ice Station POLarstern 2004 was designed to investigate physical and biological processes at the western rim of the Weddell Sea west of $50^{\circ} \mathrm{W}$ and between $70^{\circ} \mathrm{S}$ and $65^{\circ} \mathrm{S}$ during austral spring/summer. It was set up as an ice camp in the western Weddell Sea (Hellmer et al., 2008), by anchoring the R.V. Polarstern, host of the ISPOL experiment, to a multi-year ice floe, in the following referred to as the ISPOL floe. After the encounter of heavy ice en route to the proposed deployment site, ISPOL was deployed on 27 November 2004 at $68.2^{\circ} \mathrm{S}$ and $54.8^{\circ} \mathrm{W}$. The ISPOL floe partly disintegrated on 25 December 2004 requiring the relocation of some of the experiments. ISPOL ceased on 01 January 2005 with the departure of the R.V. Polarstern.

The intensive buoy deployment during ISPOL aimed to resolve meso-scale (in the order of $10-100 \mathrm{~km}$ ) sea-ice kinematics and deformation of the Antarctic pack ice under early summer conditions. The buoy-derived data provide information on high-frequency (sub-daily) ice motion and deformation that are not resolved by satellite-based sensors. These high-frequency data are crucial to determine the relative importance of tidal forcing and inertial response in the sea-ice motion and deformation fields.

In this paper the focus is on the characterisation of ice motion and deformation in the Weddell Sea during early summer. Data from spatially staggered ISPOL buoy arrays provide information on the relationship between spatial scale and magnitude of sea-ice motion (see Section 4) and of differential kinematic parameters (DKPs) (see Section 5) at the meso-scale and smaller. This, together with a buoy deployed about $100 \mathrm{~km}$ to the north, allows us to test the linearity of scale effects. Furthermore, our investigation of tidal forcing versus inertial response is critical to defining summer sea-ice drift and deformation in the western Weddell Sea. ISPOL buoys provide sea-ice data for a region where the inertial response may amplify the semidiurnal tidal forcing.

This work presents our analysis of the variance in sea-ice velocity, including the effective translation and the dependency on local bathymetry; and results from our investigation of the relative strength of tidal forcing and inertial response on sea-ice motion and deformation. In our ongoing analysis of the ISPOL buoy data we will investigate fracture patterns, which can be interpreted as sites of recurrent ice deformation events (Hibler and Schulson, 1997), and explore how to improve the description of sea-ice kinematics in numerical models via rheological parameterisations (e.g., Geiger et al., 1998b; Hibler and Schulson, 2000). Preliminary results suggest that this is especially relevant in view of changes in sea-ice rheology in response to compaction, shear and tension. Furthermore, data derived from the ISPOL deformation array have already supported the interpretation of observations on the early summer evolution of the floesize distribution (Steer et al., 2008).

\section{Sea-ice conditions during ISPOL}

The ice conditions in the region of the ISPOL buoy array were influenced by three ice regimes: second-year ice from the central Weddell Sea in the east, largely uniform first-year ice from the region of the Filchner-Ronne Ice Shelf in the centre, and heavily deformed first- or secondyear ice in the west (Hellmer et al., 2006). Across those types, ice thickness typically varied from $0.9-1.8 \mathrm{~m}$ (firstyear ice), $2 \mathrm{~m}$ (second-year ice) to $3-5 \mathrm{~m}$ (deformed ice) (Hellmer et al., 2006). Deformed ice was characterised by consolidated ridges of about $1.0 \mathrm{~m}$ height, which covered $10-20 \%$ of the surface. The sea ice in the vicinity of $I S P O L$ was covered, on average, by $0.3 \mathrm{~m}$ of cold old snow. Helicopter-borne electromagnetic ice thickness soundings in combination with in situ snow-thickness measurements showed that the overall ice and snow thickness reduced by 0.1-0.2 $\mathrm{m}$ during the ISPOL experiment, mainly due to a reduction of the snow layer. The majority of ISPOL buoys were deployed on medium to large floes within the zone of first-year ice. In situ observations show that in the vicinity of ISPOL sea ice covered in excess of $90 \%$ of the ocean surface. This is in good agreement with ice concentration data derived from $A M S R-E$ imagery (obtained from the NSIDC, USA), which show close to $100 \%$ sea-ice concentrations in the region of the ISPOL array at the end of November 2004.

\section{The $I S P O L$ buoy array}

This study of sea-ice deformation during ISPOL was made possible by four institutes sharing their resources: the Australian Antarctic Division [AAD], the Alfred Wegener Institute [AWI], the Finnish Institute of Marine Research [FIMR], and the International Arctic Research Center [IARC]. Starting on the 28 November 2004, 26 drifting buoys were deployed on the sea ice to the southwest of the ISPOL drifting ice station. Twenty-four buoys were arranged in a triangular array with side length of approximately $76 \mathrm{~km}$. However, two of these failed to operate: AWI 14955 and IARC-D; incidently both were deployed at site D (see Fig. 1 for naming convention of buoy deployment sites). In addition, one FIMR buoy (site Y) was deployed near the R.V. Polarstern to the north-east of the buoy array. It was equipped with numerous meteorological sensors in support of a study of air-ice fluxes and heat balance. A second buoy (site X) outside the deformation array had been deployed $100 \mathrm{~km}$ north of the deformation array to provide information on ice drift and meteorological conditions for analysis of synoptic-scale events. For information on buoy types and position accuracy see Appendix A.

Most of the ISPOL buoys were deployed on the 28 November 2004 (day-of-year [DoY] 333), using two 


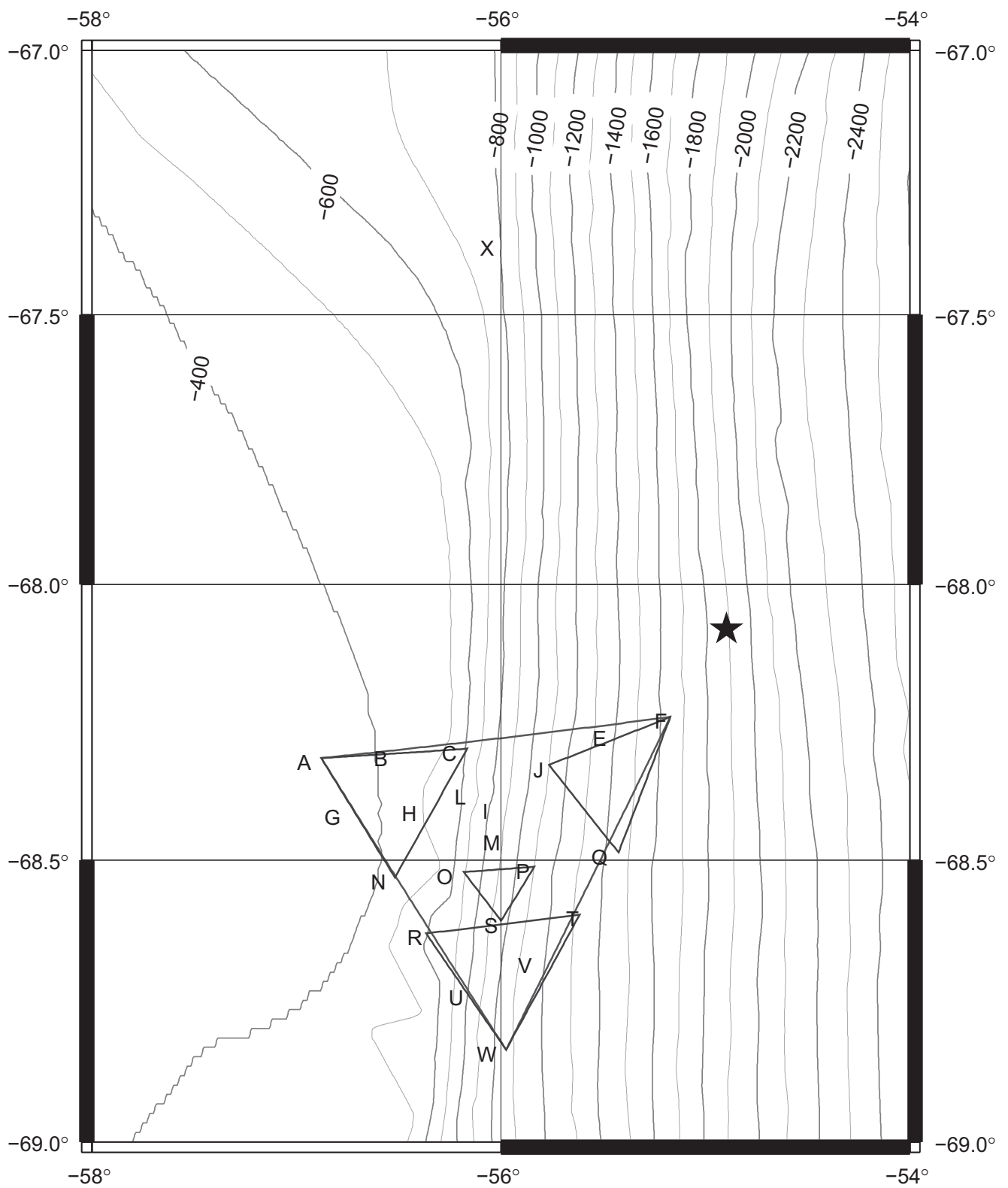

Fig. 1. Positions (for DoY (2004) 335.75) of sea-ice buoys deployed during ISPOL. Two more buoys were deployed after DoY (2004) 335.75: one at site K to the northeast of $\mathrm{L}$, and one at site Y near the ISPOL floe (black star), the later buoy outside the ISPOL array. The triangular outlines depict the five deformation arrays discussed in Section 5. Contour lines show ocean depth in metres.

helicopters. The deformation array was operational 2 days later; further buoys (at sites $\mathrm{K}$ and $\mathrm{Y}$ ) were deployed later, in early December 2004. Where possible, ice and snow thickness measurements and estimates of floe diameter, shape and surface conditions were taken at each deployment site. Upon deployment the buoys were labelled alphabetically from A to Y (Fig. 1) in order of their initial location. A was assigned to the buoy in the northwest corner; W to the southernmost buoy; and X (all Fig. 1) and $\mathrm{Y}$ to the buoys outside the deformation array.

Fig. 1 shows the positions of twenty-two of the ISPOL buoys soon after their deployment on DoY 335.75. Twenty-one of these buoys were deployed as part of an equilateral triangular deformation array with buoy spacings of approximately $12 \mathrm{~km}$ and an outer side length of approximately $76 \mathrm{~km}$. Ocean depth underneath the $I S P O L$ array varied significantly along the east-west axis of the array (Fig. 1). While the northwestern part of the buoy array was deployed over the continental shelf with water depths around $500 \mathrm{~m}$, the northeastern section of the array was deployed over deeper water (depths in excess of $1100 \mathrm{~m}$ ). Buoys deployed near the central north-south axis of the array were deployed over the continental slope. The region transected by the ISPOL array is tidally active and coincides with a local maximum in tidal currents forced by the M2 constituent (Robertson et al., 1998). 


\section{Sea-ice drift during $I S P O L$}

Sea-ice motion is in response to external forcing, such as winds and oceanic currents. This response is modulated by the material properties (including ice concentration, ice thickness, ice strength) of the sea ice itself and also by the external conditions (e.g., a nearby coastline, embedded icebergs). Associated with the seasonal changes in both the sea-ice properties and the external forcing, the motion of the sea ice varies between seasons. ISPOL presented an ideal opportunity to collect sea-ice drift and deformation data in the western Weddell Sea during a season (early summer), where there are no in situ observations for that region. The results of those buoy-derived observations are discussed in the following.

Here we consider only data collected during the ISPOL experiment. For the interval from DoY (2004) 335.59 to 361.25 data are available from 19 buoys within the ISPOL array. We consider this interval in our analysis of ice motion statistics. Cleaned buoy position data were interpolated to hourly positions and velocity was estimated via centred differencing. See Appendix A for more information on the processing of GPS data from each buoy type.

The movement of the array centroid is used to describe the general drift of the ISPOL array. The position of the array centroid is a function of positions from all buoys within the array except for the buoys at sites $\mathrm{J}, \mathrm{K}$ and $\mathrm{L}$. During ISPOL the array centroid showed net westward movement and the zonal ice drift exceeded the meridional drift by more than a factor of 3 . As can be seen in Fig. 2, the ISPOL array initially experienced net southward motion (for 2 days), followed by rapid westward motion (for 1 day). This was followed by about 2 weeks of northnorthwestward motion, during which the ice underwent sub-daily cyclic oscillations, and then northeastward motion (for 5 days). About 3 weeks after the initial net southward movement the buoy array underwent a similar southward motion, which again was followed by swift westward motion. Just before recovery of the buoy array the ice resumed movement in a net northward direction.

It can be seen from the outlines of the buoy array at the start and end of the experiment (Fig. 2) that the movement

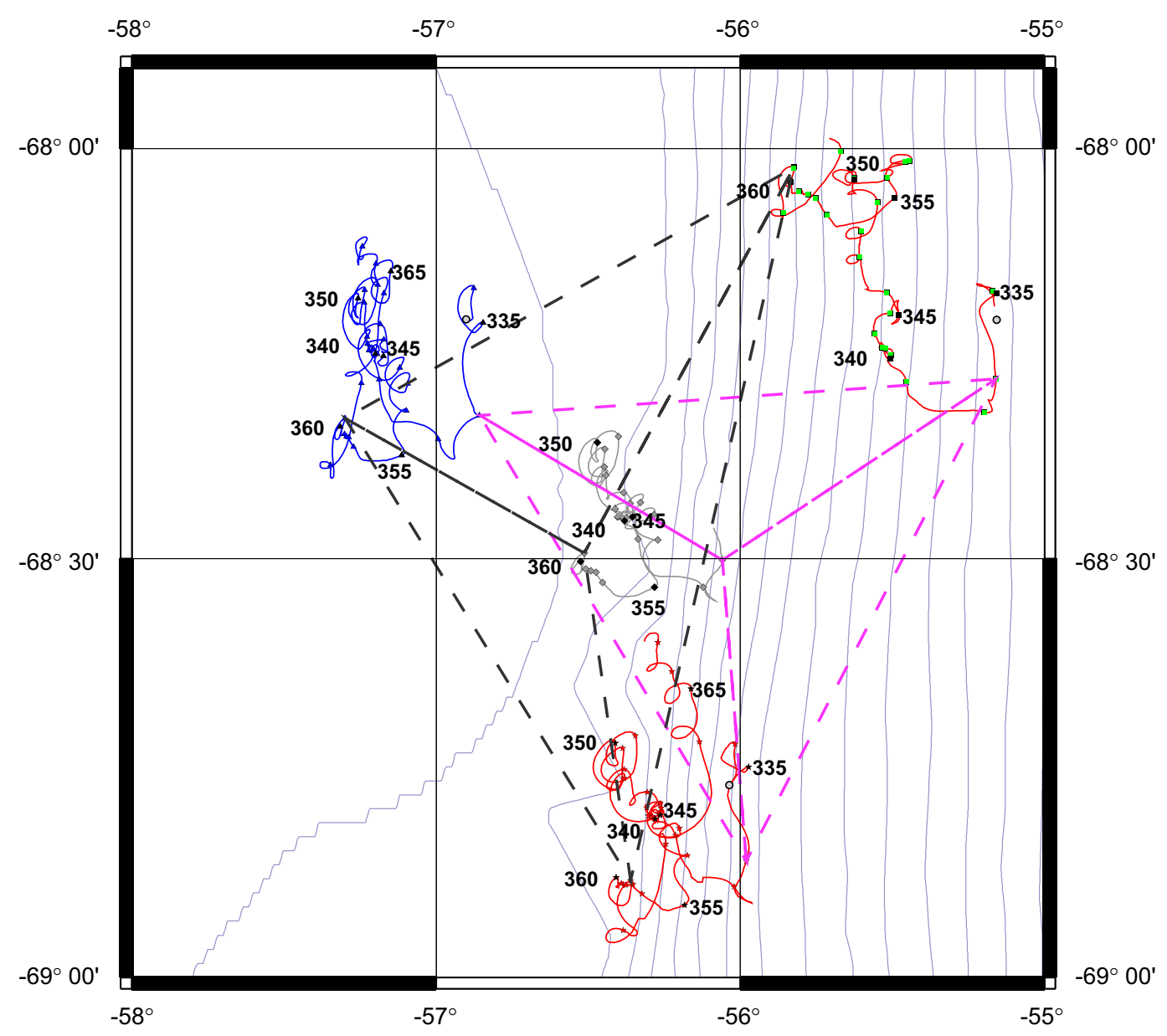

Fig. 2. Trajectories of the outer three buoys and of the array centroid of the $I S P O L$ array: Blue triangles (Buoy A), green squares (BuoyF), red stars (BuoyW) and grey diamonds (array centroid). Coloured symbols show the daily 00:00 UT locations; black symbols show the 00:00 UT locations every 5th day. Black labels denote the DoY (2004) for the latter. Grey circles depict the deployment position for the three corner buoys. The shape of the outer triangle [AFW] (with connections to the array centroid) is shown for DoY 336 (dashed mauve) and for DoY 361 (dashed grey). 


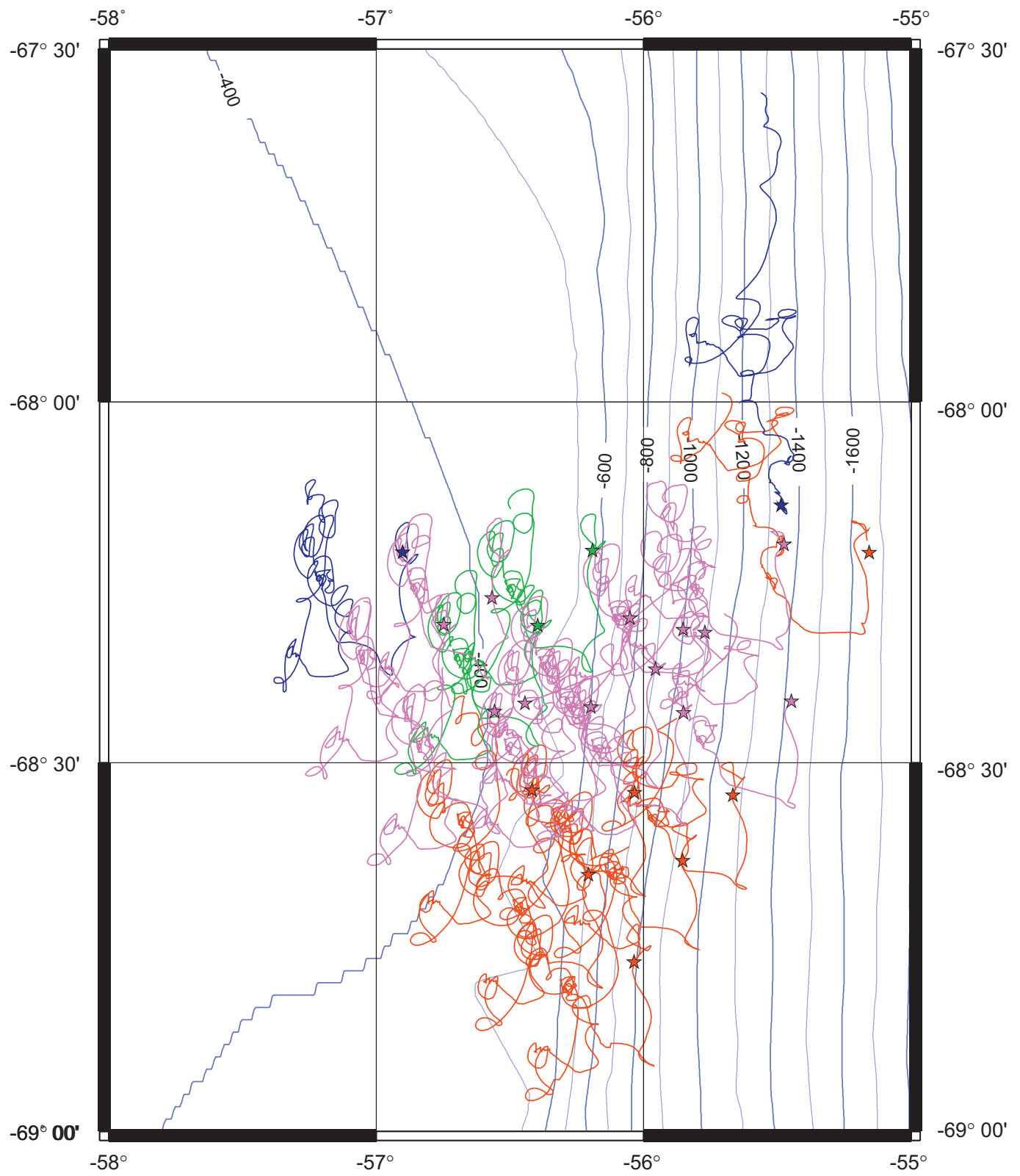

Fig. 3. Drift trajectories of the ISPOL array as well as for buoy Y deployed later (on DoY 338.46) near the ISPOL floe. All data are shown from buoy deployment to recovery, spanning about 1 month. Stars indicate the deployment positions of the buoys. Trajectory colours indicate the buoy owner: FIMR (blue), AWI (green), IARC (mauve) and AAD (red).

of the sea ice within the array was not uniform. The shape of the initial outer perimeter of the array (at DoY 336) may be approximated as an equilateral triangle, with the array centroid slightly offset to the northwest of the geometric centre. Just before the recovery of the buoy array, on DoY 361 , the outer array perimeter may be described as an isosceles triangle with a stretched base between sites $\mathrm{F}$ and W. Details of this differential motion will be discussed later (see Section 5). For now we investigate the inhomogeneous character of the sea-ice drift during ISPOL.

Fig. 3 shows all drift trajectories within the ISPOL array plus the trajectories of the meteorological buoy (site Y) deployed near the ISPOL floe. It should be noted that the complete ISPOL time series for each individual drift trajectory is shown. At first impression the sea-ice motion appears to be spatially coherent. Closer investigation of individual velocity traces (Fig. 4), however, reveals a gradient through the array, with sea ice in the northeastern part of the array experiencing larger net translation and less high-frequency looping. This was also observed at the ISPOL floe. Motion recorded at the northwestern and southern buoy sites (sites A and W), on the other hand, exhibit notably larger ice-motion amplitude, especially at daily cycles and for the meridional velocity component. To investigate the spatial differences in sea-ice velocity we consult daily $A M S R-E$ data, which show little spatial variability in the sea-ice concentration across the ISPOL array: At all times during the experiment ice concentrations 

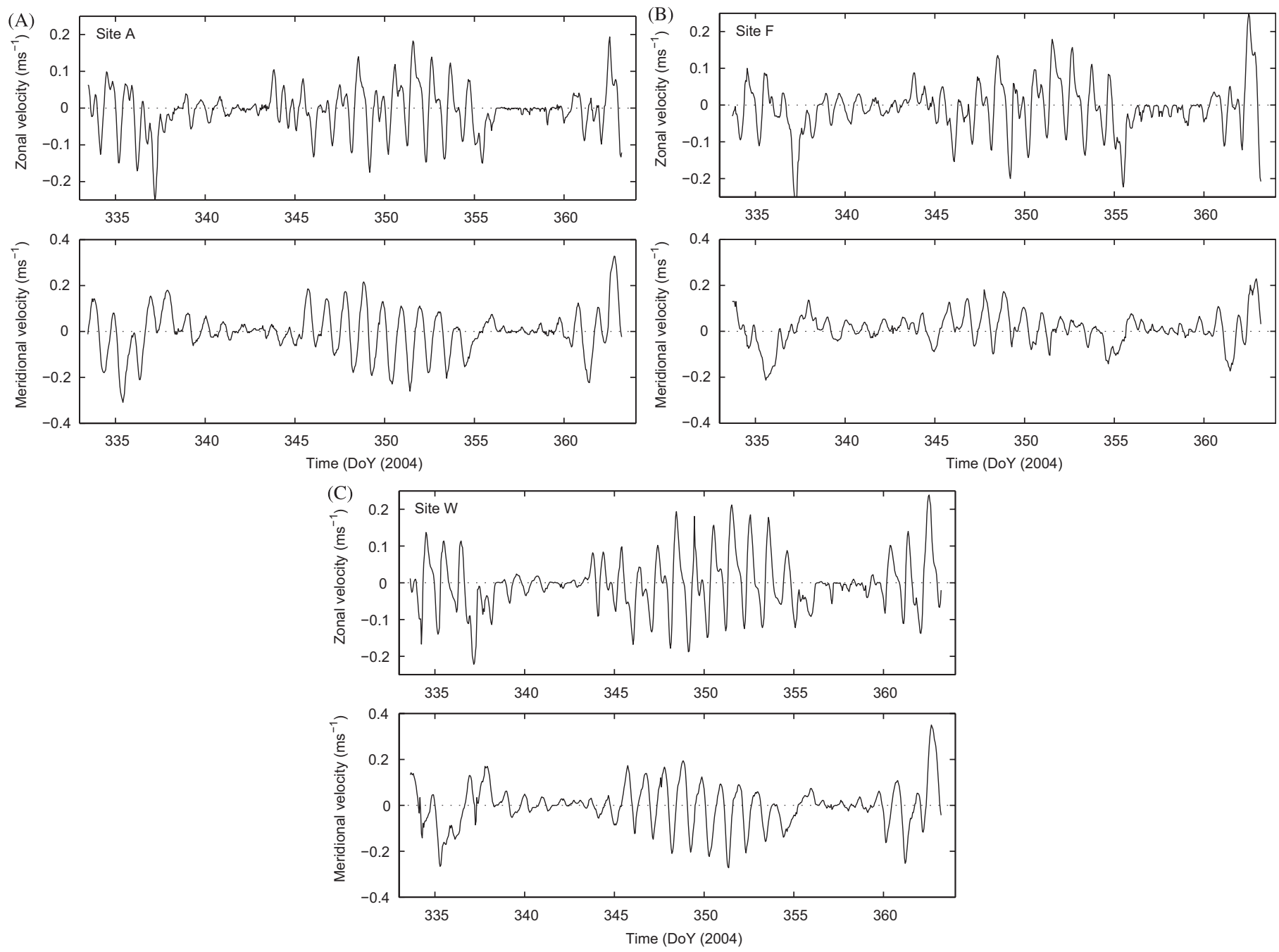

Fig. 4. Velocity traces for the zonal and meridional components of the ice drift as measured at the three corner points of the ISPOL array: (A) at site A, (B) at site $\mathrm{F}$ and (C) at site $\mathrm{W}$.

remained above $95 \%$ within the $I S P O L$ region, and often close to $100 \%$. Within this range of ice concentrations, $A M S R-E$ data indicate highest concentrations were located in the northwestern and southern parts of the ISPOL array. We suggest that the spatial differences in sea-ice drift within the ISPOL array are due to bathymetric forcing, most likely associated with tidal forcing.

Noteworthy are two quiescent intervals during ISPOL: DoY 339-344 and 355-360. During these two intervals all buoys experienced a reduction in rate of translation and a reduction in amplitude of cyclic oscillations. The quiescent intervals correspond to times of reduced $\mathrm{K} 1$ and $\mathrm{M} 2$ tidal amplitude (McPhee, 2008). During the quiescent intervals atmospheric surface pressure was mostly steady, with moderate winds from the south during the first interval and from the northwest during the second interval. $A M S R-E$ derived sea-ice concentrations do not indicate a sufficient increase in sea-ice concentration to suggest stagnation of the ice drift. Further discussion of these two intervals will be presented in Section 5 .
To investigate the spatial differences of ice motion we analyse the velocity variance across the ISPOL array (Section 4.1), derive the associated meander coefficients (Section 4.2), and investigate the ISPOL drift in the frequency domain (Section 4.3).

\subsection{Summer sea-ice velocity variance}

As described above, while the zonal ice velocity exceeded the meridional velocity by more than a factor of 3 , the meridional velocity variance dominates during the 26-day lifetime of the ISPOL array (Fig. 5). This is especially true for the drift within the northwestern section of the deformation array. The variance in ice velocity is closest to isotropic in the far northeastern part of the array (site F) and at the remote site $X$ (not shown in Fig. 5). The ratio of zonal to meridional net ice translocation is atypically small for ISPOL buoys in the western part of the array, where water depth is less than $1200 \mathrm{~m}$. This is associated with an increase in meridional velocity variance from east to west. 


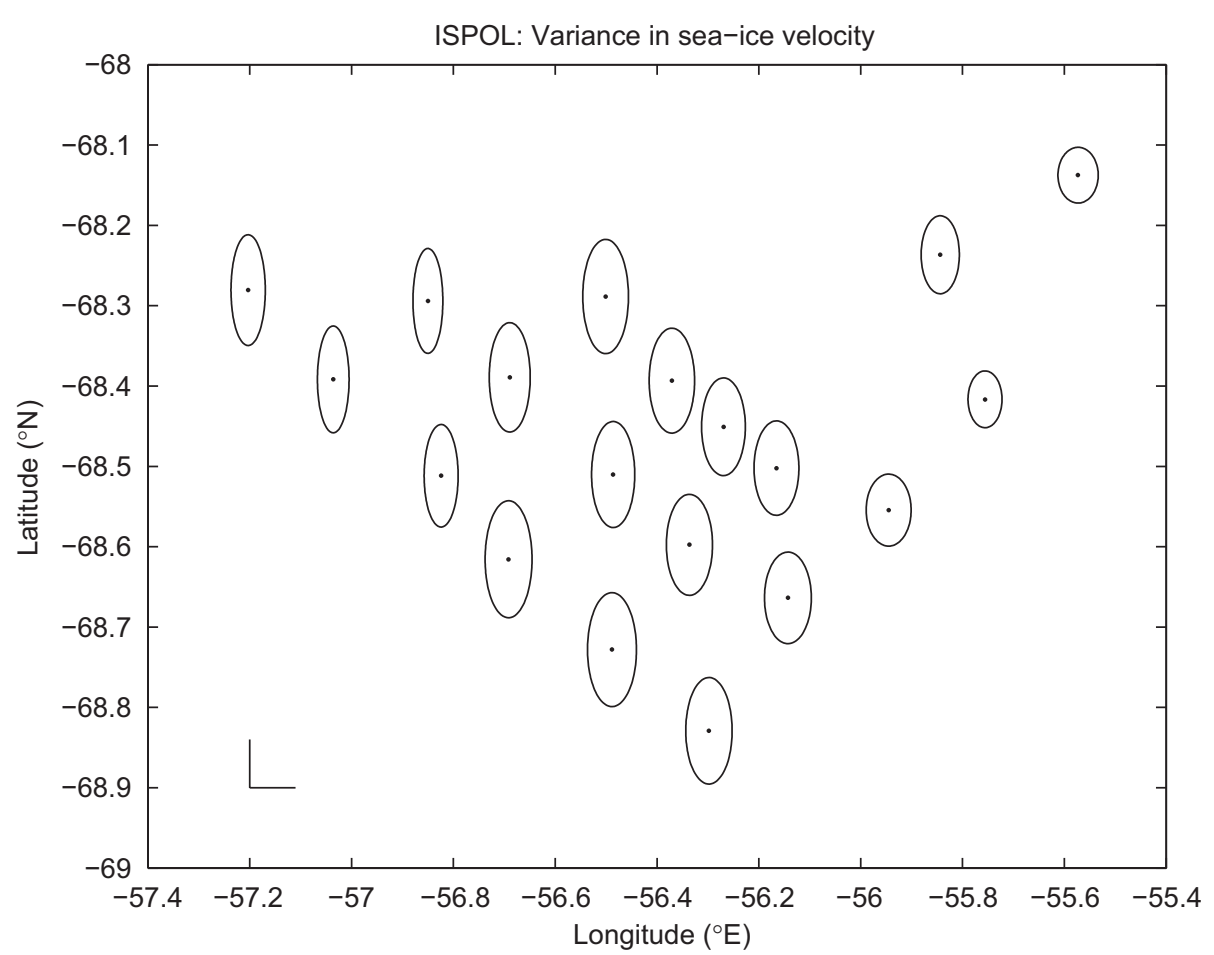

Fig. 5. Variance in sea-ice velocity for the ISPOL array for the common time interval from DoY(2004) 336.208 to 361.292 . The scale (bottom left) shows $0.005 \mathrm{~m}^{2} \mathrm{~s}^{-2}$ for each direction.

Our analysis of $A M S R-E$ data over the ISPOL interval shows that sea-ice concentration across the $I S P O L$ array did not vary sufficiently $(<1 \%)$ to explain the inhomogeneous distribution of velocity variance identified above (Fig. 5).

Mean buoy separations between pairs varied from 12 to $121 \mathrm{~km}$ during ISPOL. Cross-correlations have been derived for the velocity time series of all buoy pairs, including those from the buoy at site Y. For these separation scales the lowest horizontal correlation coefficient is 0.32 for 1 -hourly ice velocities. Correlations of the zonal ice velocities are above 0.8 everywhere within the buoy array, while the correlations of the meridional ice velocities drop below 0.8 at buoy separations of $60 \mathrm{~km}$ or more. The associated east-west gradient in meridional ice velocity is likely to be driven by the underlying topography and associated processes, such as tidal currents, as well as proximity to the coastline. At separation lengths of $70 \mathrm{~km}$ or less the ice drift is coherent. At larger separations the zonal correlations degrade faster than the meridional, due to the dominant meridional drift.

\subsection{Meander coefficients}

To assess the effective translation associated with the sea-ice drift we define the meander coefficient, which relates the overall translocation of the buoy to its net translation. Here we calculate a local meander coefficient, which is the ratio of the total buoy trajectory length covered within the common time interval from DoY 335.59 to 361.25 to the net displacement over the same time interval. A meander coefficient of one means the buoy is moving on a direct line, while a high meander coefficient indicates an erratic trajectory (e.g., Massom, 1992; Heil and Allison, 1999) (Fig. 6).

There is a large gradient across the ISPOL array for the spatial distribution of meander coefficients (Fig. 6). For the common interval most of the sea ice within the ISPOL array underwent considerable repeated anticlockwise motion, which is reflected in high meander coefficients (above 8.0). Conversely, the sea ice in the northeastern part of the array (sites $\mathrm{E}$ and $\mathrm{Q}$ ) exhibit significantly lower meander coefficients, and the eastern most site (site F) exhibited the lowest meander coefficient. Those sites measure the ice drift over deeper waters (water depths of more than $900 \mathrm{~m}$ ). We find the highest values of meander coefficient at site A and for the sea ice in the southernmost third of the ISPOL array. The meander coefficient at northernmost site $\mathrm{X}$ is similar to the highest recorded within the $I S P O L$ array. These sites are all over shallow water, less than $700 \mathrm{~m}$ deep, where we can expect ocean tides to induce more short-term motion than at sites off the shelf. The spatial differences in the ice motion across the array will be further analysed in the next section.

\subsection{Frequency analysis}

Time series of sea-ice drift can be decomposed into a signal due to the mean translation and a signal due to overlying variability. Power spectral analysis (Jenkins and 


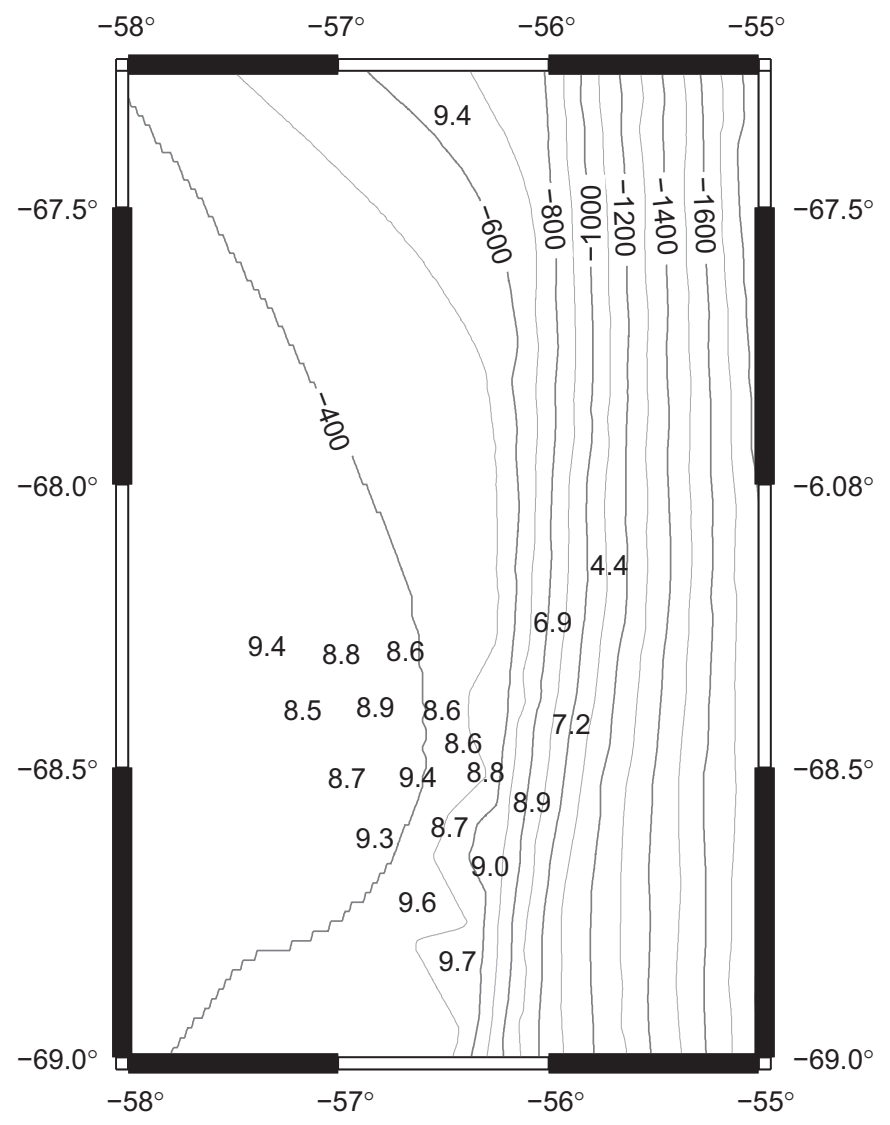

Fig. 6. Spatial distribution of meander coefficients for the ISPOL array and the remote buoy ( ite $\mathrm{X}$ ) for the common time interval from DoY (2004) 335.59 to 361.25. Bathymetric contours (m) are also shown.

Watts, 1969) allows us to view the data in the wavenumberfrequency domain, where the variance of stochastic processes is distributed with frequency. For discretely sampled data, such as the ISPOL buoy data, we apply a fast Fourier transform (FFT). To avoid frequency leakage associated with our discrete time series, we use a Hamming window (Press et al., 1990) in the time domain to sharpen the spectral peaks while minimising any spectral leaks. Using hourly time series the Nyquist frequency for our data is 12 cycles day $^{-1}$, which is adequate to resolve the highest frequency processes (semidiurnal tides, inertial response) we are concerned with. The length of the ISPOL time series is sufficient to resolve the frequency range of large-scale atmospheric forcing, which following Jones and Simmonds (1993), can be framed at 0.125-0.333 cycles day $^{-1}$ for extratropical cyclones.

The relatively short time series of buoy-derived data constrains the frequency resolution at which the Fourier analysis can be performed. Furthermore, to increase our confidence in the derived frequency spectra, we chose to split our finite time series in three overlapping intervals (Press et al., 1990). The overall distribution of power spectral density is obtained as the normalised sum over all realisations, hence increasing the likelihood that the derived frequency spectrum converges toward the true distribution. This approach limits us to resolve 128 frequency bins within the spectral range of our data.

Fig. 7 shows the power spectral density distributions for the zonal and meridional velocity magnitudes of the three corner sites A, F and W. Error estimates have been derived following Jenkins and Watts (1969). The striking features in the power spectral densities for all sites are the peaks at 1 and 2 cycles day ${ }^{-1}$. These peaks are associated with physical processes of the oceanic tidal motion (at about 1 and 2 cycles day ${ }^{-1}$ ) and the inertial response (at about 2 cycles day $^{-1}$ ). Interestingly, the ice motion associated with the daily oceanic tide exceeds that associated with any ice motion at longer periods, such as ice motion due to wind forcing derived from passing cyclonic systems. This behaviour has been found for all sites within the ISPOL array, and indicates that oceanic tides may exert substantial forcing on the sea ice, especially at times of moderate atmospheric conditions. This is a significant finding; generally cyclonic systems provide the major forcing of Antarctic ice motion, regardless of the season.

Across the ISPOL array, the strongest peak in power spectral density of ice motion is consistently at frequencies around 1 cycle day $^{-1}$, for both horizontal velocity components. However, there is some variability across the ISPOL array: in the meridional component there is an east-west gradient for power associated with forcing at 2 cycles day $^{-1}$. For example, site $A$ in the far northwest of the array exhibits the least amount of power spectral density at semidiurnal frequencies. There is a similar east-west gradient for the total power contained in the zonal and meridional components. For all sites except F, Q and $\mathrm{T}$ the power contained in the meridional component exceeds that in the zonal component. At site F, however, power spectral density associated with the zonal component is about 35\% larger than that of the meridional. For sites $\mathrm{Q}$ and $\mathrm{T}$, which are also on the eastern edge of the ISPOL array but south of site $\mathrm{F}$, this difference is only about $8 \%$. In the northeastern section of the ISPOL array and near the site $X$ (about $110 \mathrm{~km}$ to the north of the $I S P O L$ array) the relative input of low-frequency forcing on sea-ice motion is larger than for the remainder of the buoy array. The lowest signal of low-frequency forcing has been observed in the northwestern part of the array. This difference between the sites is likely to be associated with local ice characteristics, especially the compactness of the pack.

To analyse the high-frequency component of the icevelocity frequency spectra, the integrated power spectral densities for diurnal and semidiurnal processes have been plotted separately (Fig. 8) for all buoys deployed from DoY 335.59 to 361.25. At site $\mathrm{X}$ the energy associated with motion at both these frequencies by far exceeds those measured at any other site. This is likely due to the lower ice concentration (on average about 82\%) at site $\mathrm{X}$ compared to ice concentrations near the ISPOL array (on average over 94\%). This allows the sea ice to respond to high-frequency forcing with an amplitude larger than 

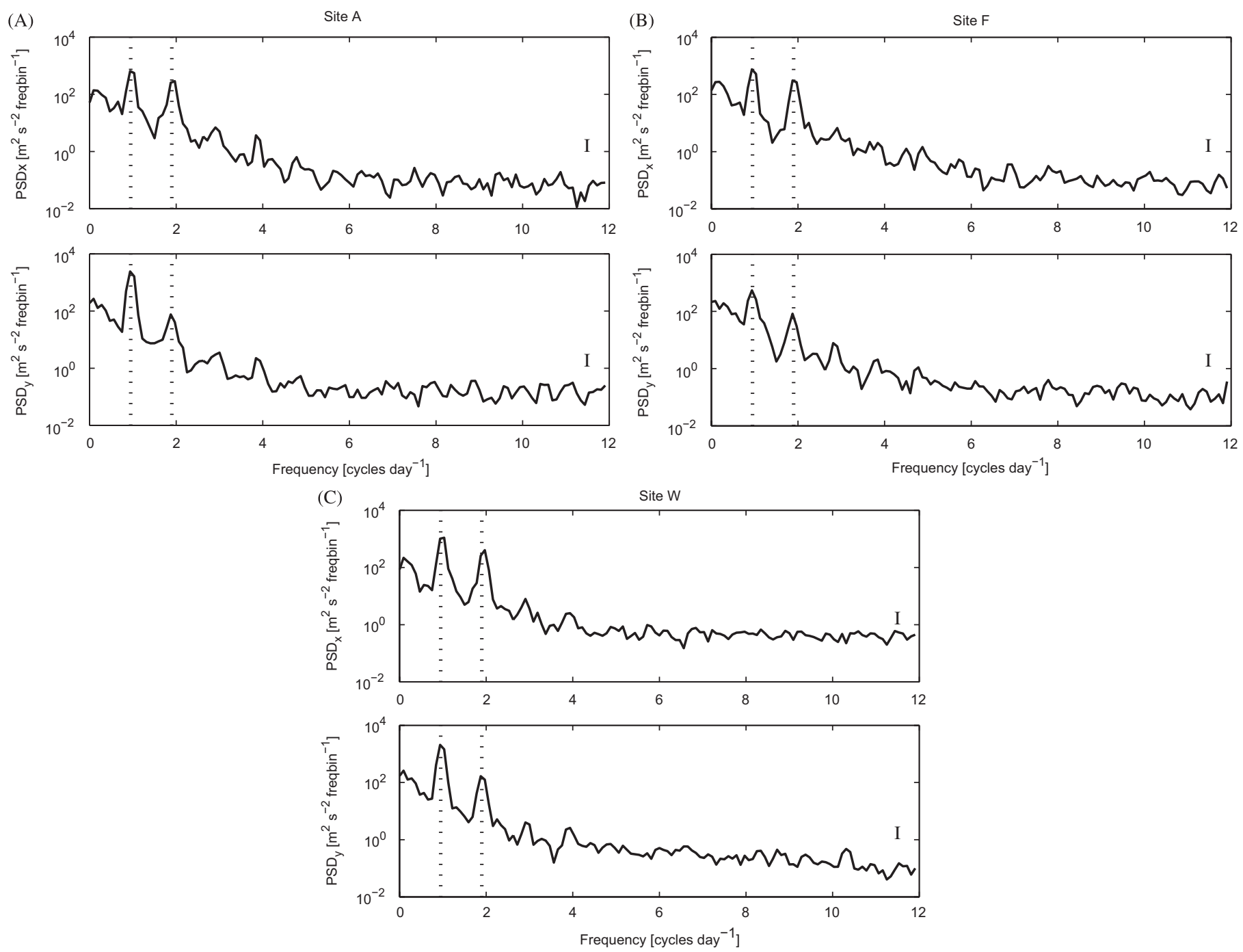

Fig. 7. Power density spectra of the zonal (top panel) and meridional (bottom panel) components for (A) at site A, (B) at site F and (C) at site W. Solid vertical lines at 11.5 cycles day ${ }^{-1}$ show the $90 \%$ confidence intervals (based on the $t$-distribution (Little and Rubin, 1987)).

observed at the ISPOL array (Thorndike, 1986). Across the ISPOL array itself, the magnitude of diurnal tides was strongest in the western part of the array where the water is shallower. Amplitudes of the semidiurnal processes decreased from the north to the south of the array (as did the total high-frequency power spectral density), and do not seem to exhibit a dependency on ocean depth. This may be taken as an indication that the inertial response of the sea ice contributes substantially to ice motion at semidiurnal frequencies. In the following we seek to distinguish between processes at semidiurnal frequencies.

The periods of the semidiurnal tidal motion are 12.4 (M2) and $12.0 \mathrm{~h}(\mathrm{~S} 2)$, which are very close to the period of the inertial response $(12.9 \mathrm{~h})$ in the region of interest. Energy associated with both processes is distributed over the same frequency bins. Hence, Fourier analysis as described above, does not allow one to distinguish between those processes. On the other hand, rotary spectral analysis makes use of the fact that a translation within a twodimensional plane may also be expressed as a combination of clockwise and anticlockwise motion instead as by motion components along two coordinate axis. This presentation is useful when we seek to distinguish two processes with near identical energy distribution over frequency. For our data this implies that the tidal motion, which describes a full ellipse every period, can be separated into a barotropic (or clockwise in the Southern Hemisphere) and a baroclinic (or anticlockwise in the Southern Hemisphere) motion (Robertson et al., 1998). Motion associated with the inertial response, on the other hand, is strictly anticlockwise in the Southern Hemisphere. Hence the rotary spectra might allow us to distinguish between these processes in the ice-velocity spectra.

Examples of the rotary spectral analysis of sea-ice drift during ISPOL are shown in Fig. 9, where the power spectral density associated with the anticlockwise (clockwise) velocity component has been plotted over positive (negative) frequencies. At all sites the frequency spectra of sea-ice velocity are dominated by diurnal (and to a lesser degree by semidiurnal) peaks in the clockwise 


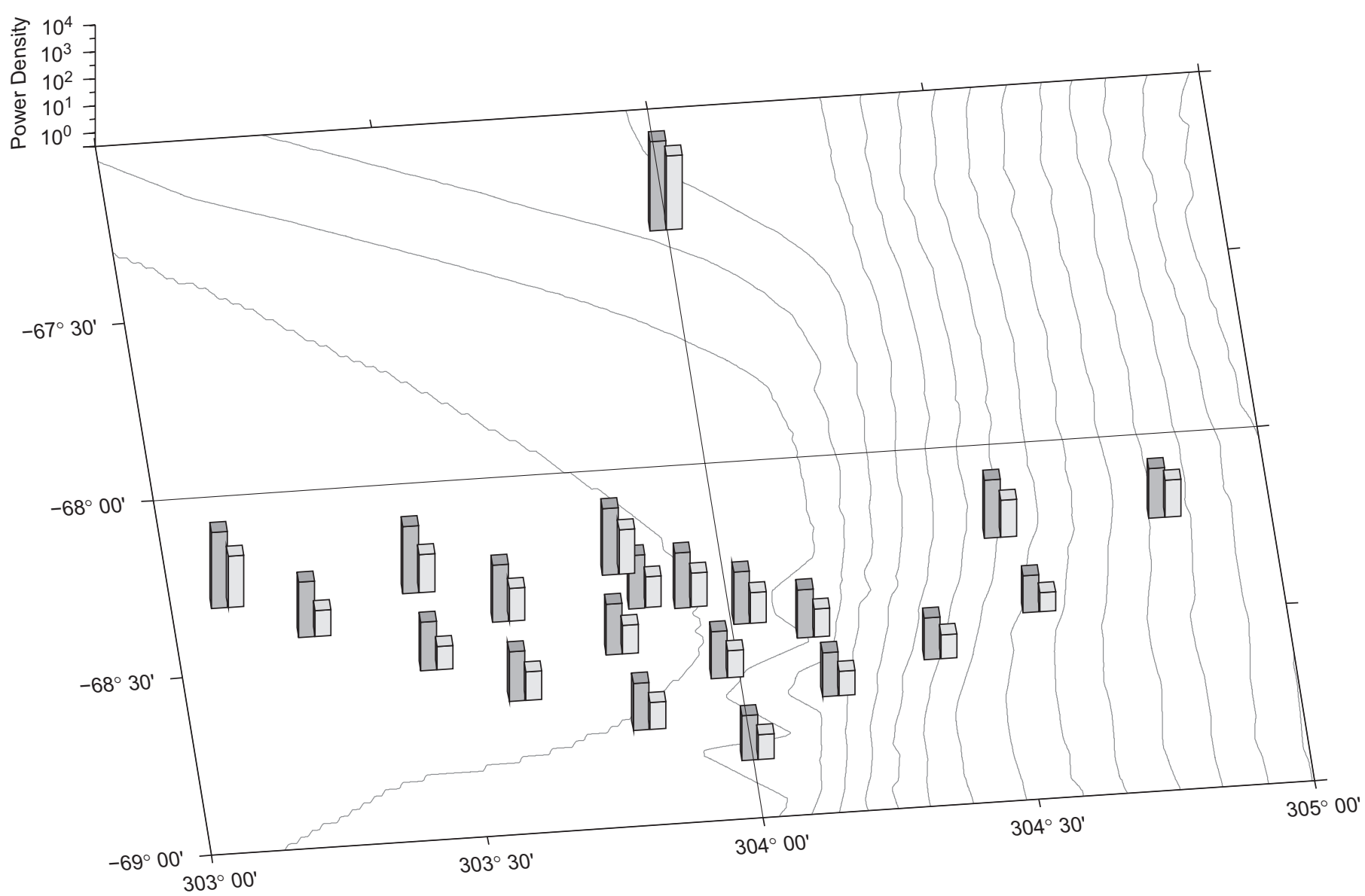

Fig. 8. Spatial distribution of the intergrated power spectral density of sea-ice motion at diurnal ( $1 \mathrm{cycles}^{-1} \mathrm{y}^{-1}$; dark grey) and semidiurnal $\left(2\right.$ cycles day ${ }^{-1}$; light grey) frequencies. Also shown are the bathymetric contour lines (contour spacing is $100 \mathrm{~m}$. See Fig. 1 for contour values).

component. At all sites the semidiurnal signal is about one order of magnitude less than the diurnal signal. Sites A and $\mathrm{W}$, which are on the continental shelf, exhibit stronger daily signals than site $F$, which is just off the shelf. In the clockwise part of the spectrum the diurnal and semidiurnal are higher than in the anticlockwise part. Processes at diurnal and semidiurnal periods and those at low frequencies, including synoptic-scale processes, are all of similar magnitude in the anticlockwise part of the spectrum.

Following Wunsch (1975) baroclinic tides only propagate freely in regions where the tidal frequency exceeds the inertial frequency. The latitude at which tidal and inertial frequencies are identical is called the critical latitude. Moreover, ISPOL was deployed poleward of the critical latitude for the daily tidal constituents. Hence only barotropic diurnal tides exist in the ISPOL region. The results from our rotary spectral analysis are consistent with the tidal processes: Signals for the diurnal and semidiurnal barotropic tides are apparent in each of the three spectra (Fig. 9, negative frequencies). From a tidal model (Robertson et al., 1998) we derive the ratio of 2.1 for the M2 clockwise over the anticlockwise components in the ISPOL region. From ISPOL measurements the clockwise to anticlockwise ratio for the semidiurnal frequency are 2.1 (Site A), 0.87 (Site F) and 2.1 (Site W). These data indicate that for sea ice at sites $\mathrm{A}$ and $\mathrm{W}$ the semidiurnal signal is likely to be dominated by tidal forcing, while at site $\mathrm{F}$ the semidiurnal signal is likely due to a combination of tidal forcing and inertial response. Most other ISPOL sites exhibit a clockwise to anticlockwise ratio for the semidiurnal frequency between 1.9 and 2.4. Except for site F, only sites $\mathrm{E}$ and $\mathrm{Q}$ had a ratio lower than 1.9.

Our findings confirm that tidal forcing contributes significantly to the ice velocity variance in the Weddell Sea, which is dominated by diurnal tides. Furthermore, over the continental shelf, ice motion at semidiurnal frequencies is dominated by tidal forcing, while there is evidence that sea ice off the shelf responds inertially (Vihma and Launiainen, 1993).

\subsection{Atmospheric forcing}

On long time scales sea-ice drift follows the oceanic surface currents (e.g., Thorndike and Colony, 1982; Budd, 1986), which themselves are a combination of wind-driven and geostrophically forced currents, and describe a basinwide cyclonic gyre with intensified velocities in the 

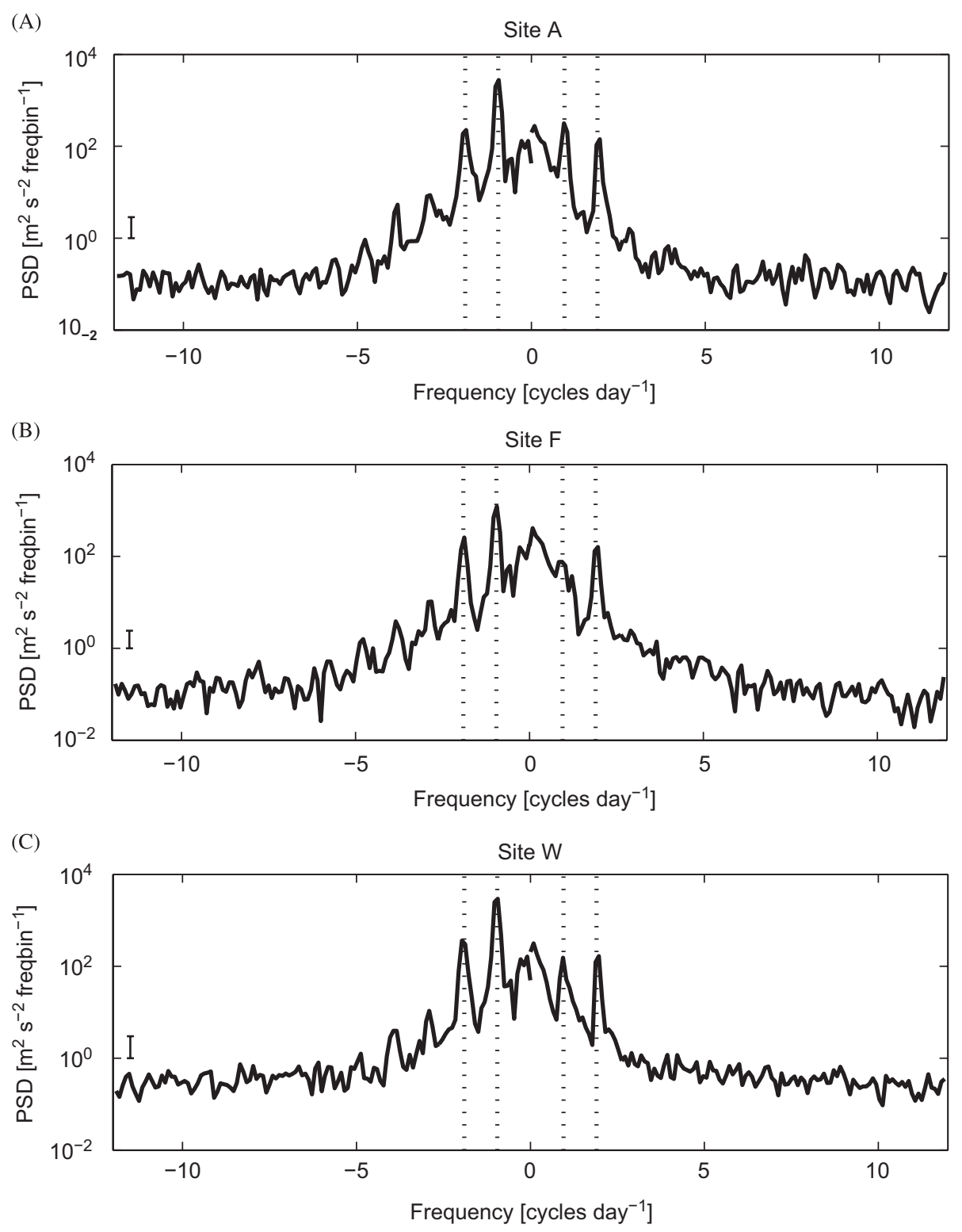

Fig. 9. Power density spectra of the anticlockwise (positive frequencies) and clockwise (negative frequencies) components (A) at site A, (B) at site $\mathrm{F}$ and (C) at site W. Solid bars at -11.5 cycles day ${ }^{-1}$ show the confidence interval for each of the spectra. Vertical dotted lines indicate diurnal and semidiurnal frequencies.

boundary currents (e.g., Deacon, 1984). The cyclonic ocean circulation is likely to be driven by a combination of Ekman pumping and topographic steering. On shorter time scales (i.e. over several days) the sea ice responds readily to atmospheric forcing. To investigate the response of sea ice in the ISPOL region to atmospheric forcing we use data obtained from the weather station aboard the R.V. Polarstern. Wind speeds were obtained at a height of $38.9 \mathrm{~m}$ and are translated to the $10 \mathrm{~m}$ reference level assuming a logarithmic wind profile in a neutral atmosphere (Fig. 10).

During ISPOL the mean ratio of ice drift to wind speed (at the $10 \mathrm{~m}$ reference level) was 0.016 for the interval from DoY (2004) 333 to 363 . This is comparable with the ratio of 0.018 obtained for the western Weddell Sea by Vihma et al. (1996) from IWS-1 buoy deployments. Those are lower than winter observations of the mean speed ratio of 0.032 in the central Weddell Sea during winter (Martinson and Wamser, 1990), or 0.031 near Maud Rise (McPhee et al., 1996). At the same time there was only a moderate correlation $\left(R^{2}=0.54\right)$ between wind speed and ice drift, which is low compared to correlations derived during other seasons or other locations. Our findings are confirmed by McPhee (2008), who compares derived $10 \mathrm{~m}$ wind speed from measurements at the R.V. Polarstern with the ice drift of the ISPOL floe. He finds an average ratio of 0.015 for the interval from DoY (2004) 336 to 367.

Fig. 10 shows the temporal traces of the sea-ice velocity magnitude at site $\mathrm{F}$ and the $10 \mathrm{~m}$ wind-speed magnitude. As can be seen, the sea ice responds closely to atmospheric 


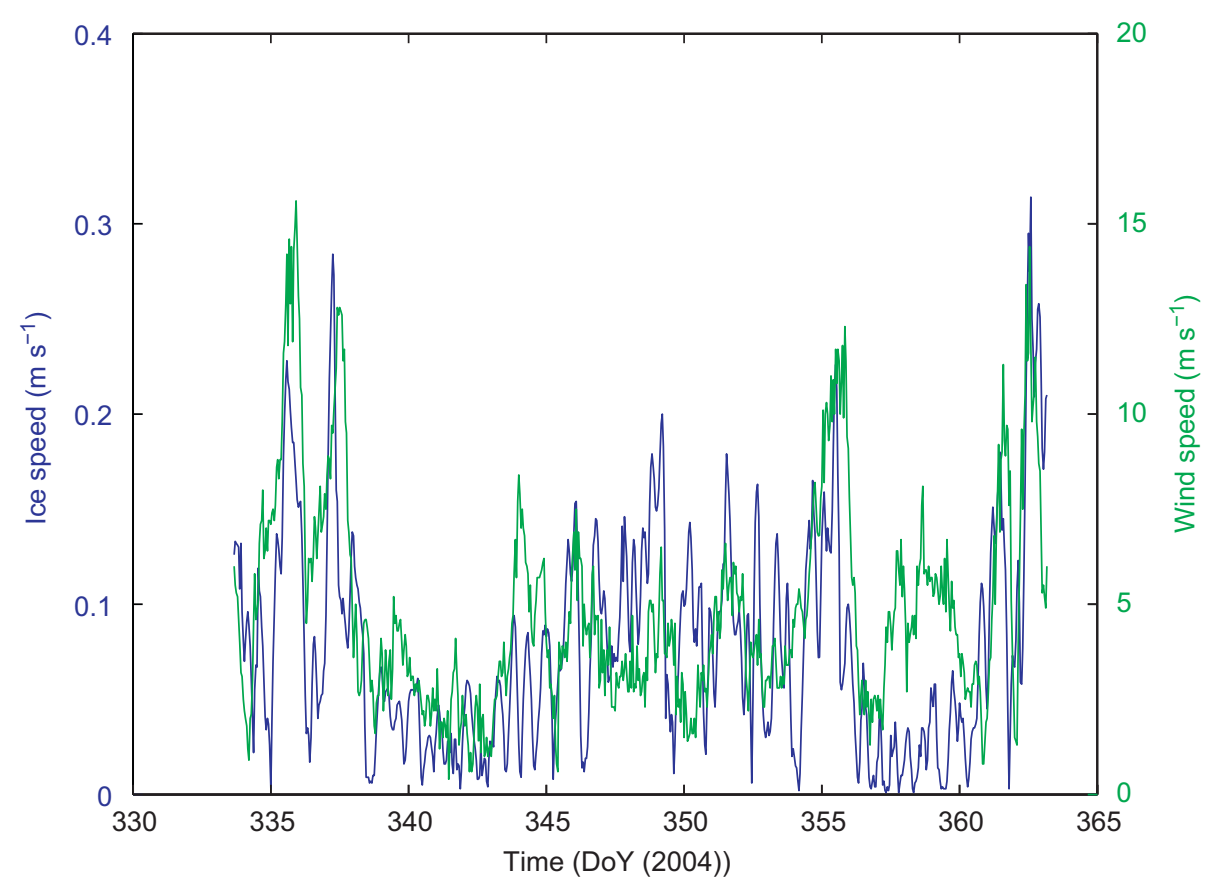

Fig. 10. Time series of sea-ice velocity magnitude from site $\mathrm{F}$ (blue, left $y$-axis) and the $10 \mathrm{~m}$ wind-speed magnitude (green, right $y$-axis) derived from data from the R.V. Polarstern's weather station.
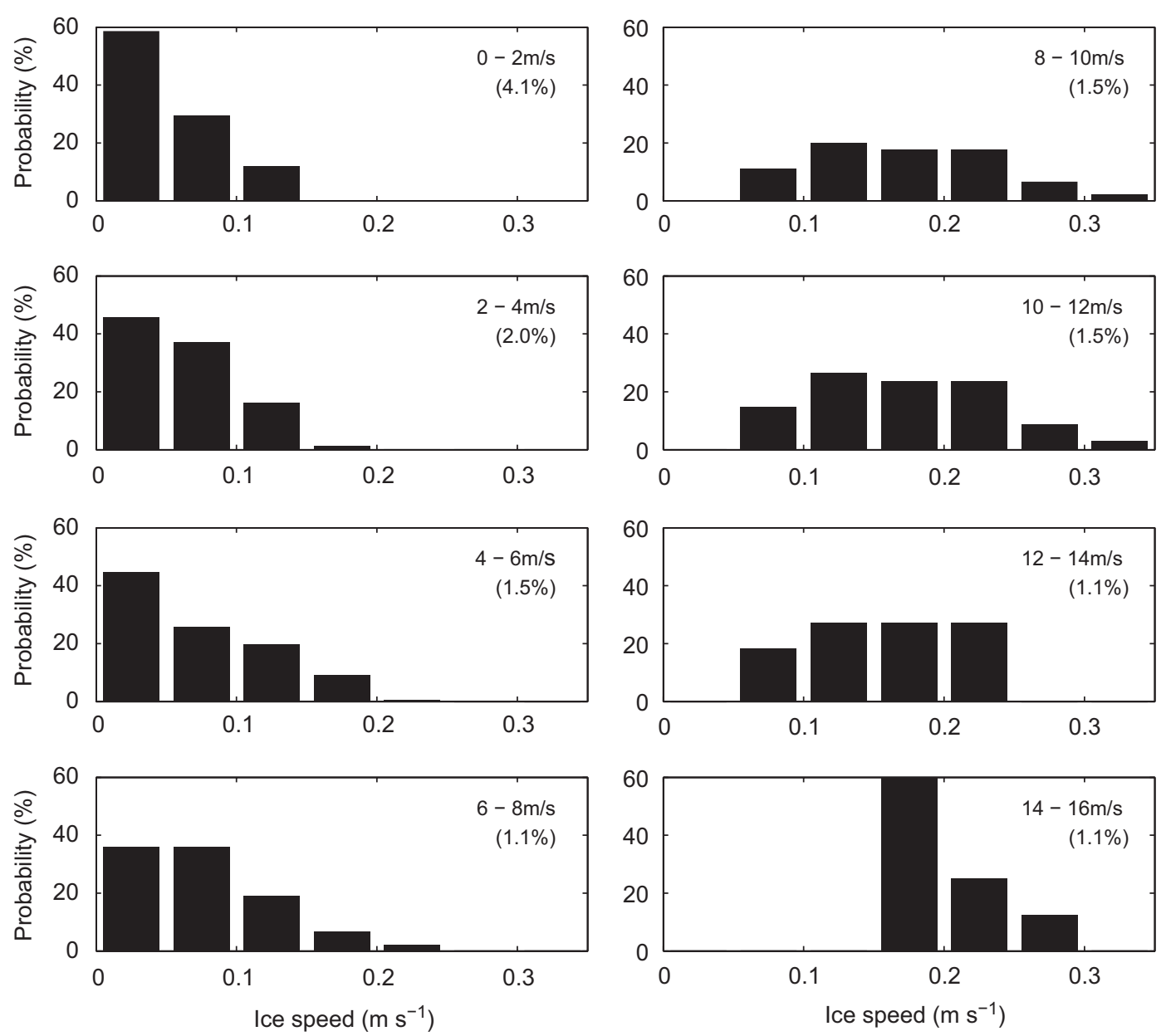

Fig. 11. Distribution of sea-ice velocity at site $\mathrm{F}$ for $2 \mathrm{~m} \mathrm{~s}^{-1}$ magnitude bands of wind speed. The mean ratio of ice speed to wind speed for each windspeed class is shown in brackets. 
forcing for wind speeds above $8 \mathrm{~m} \mathrm{~s}^{-1}$. However, for lower wind speeds the sea ice may (e.g., DoY 347) or may not (e.g., DoY 357) follow changes in the wind forcing. A similar result has been found by McPhee (2008) when comparing wind speed and low-pass filtered (omitting diurnal and higher frequencies) ice motion.

Fourier analysis (not shown here) of the atmospheric forcing obtained at the R.V. Polarstern's weather station reveals a red spectrum, with little energy (less than 12\%) at frequencies higher than 0.375 cycles day $^{-1}$. Atmospheric processes during ISPOL were largely determined by the passage of low-pressure systems. The different shapes of the spectra of wind velocity and sea-ice velocity (Section 4.3) give evidence that atmospheric changes do not play the major role in inducing ice-velocity variance. This is in agreement with the relatively moderate correlation between wind speed and ice drift identified above, and underlined by the bimodal behaviour of sea-ice velocities relative to wind velocity (Fig. 11). The ratio of ice speed to wind speed is relatively large for wind-speed categories below $4 \mathrm{~m} \mathrm{~s}^{-1}$ (in $2 \mathrm{~m} \mathrm{~s}^{-1}$ bins). At higher wind speeds the ratio of ice speed to wind speed drops to below $2 \%$. Similarly the shape of the probability distribution for ice speeds as function of the wind-speed class changes: For wind speeds below $6 \mathrm{~m} \mathrm{~s}^{-1}$ the probability for sea ice to exhibit a given speed (in $0.05 \mathrm{~m} \mathrm{~s}^{-1}$ bins) decreases linearly from very slow motion to about $0.2 \mathrm{~m} \mathrm{~s}^{-1}$, while at wind speeds above $6 \mathrm{~ms}^{-1}$ ice speeds are normally distributed.

Taking these results into consideration with the analysis presented in Section 4, we conclude that during ISPOL the sea ice was not in free drift, but instead constrained by internal ice forces. We also find that forcings due to tidal currents and inertial response play a significant role in the force balance on the ice pack, whereas direct forcing through winds is less significant than found in previous studies.

\section{Sea-ice deformation during $I S P O L$}

To assess sea-ice motion within the ISPOL array the DKPs can be calculated. Assuming that sea ice can be represented as a homogenous continuum, we follow Kirwan (1975) and Molinari and Kirwan (1975) to derive the four constituent DKPs, namely divergence $(D)$, vorticity $(V)$, shear deformation $(S)$ and normal deformation $(N)$ from the strain components. Here we derive the kinematic parameters relative to the array centroid, hence excluding any effect of long-term drift.

\subsection{Sea-ice deformation of the ISPOL arrays}

The distribution of mean ice drift (Fig. 12) during ISPOL shows not only an unusual mean drift direction

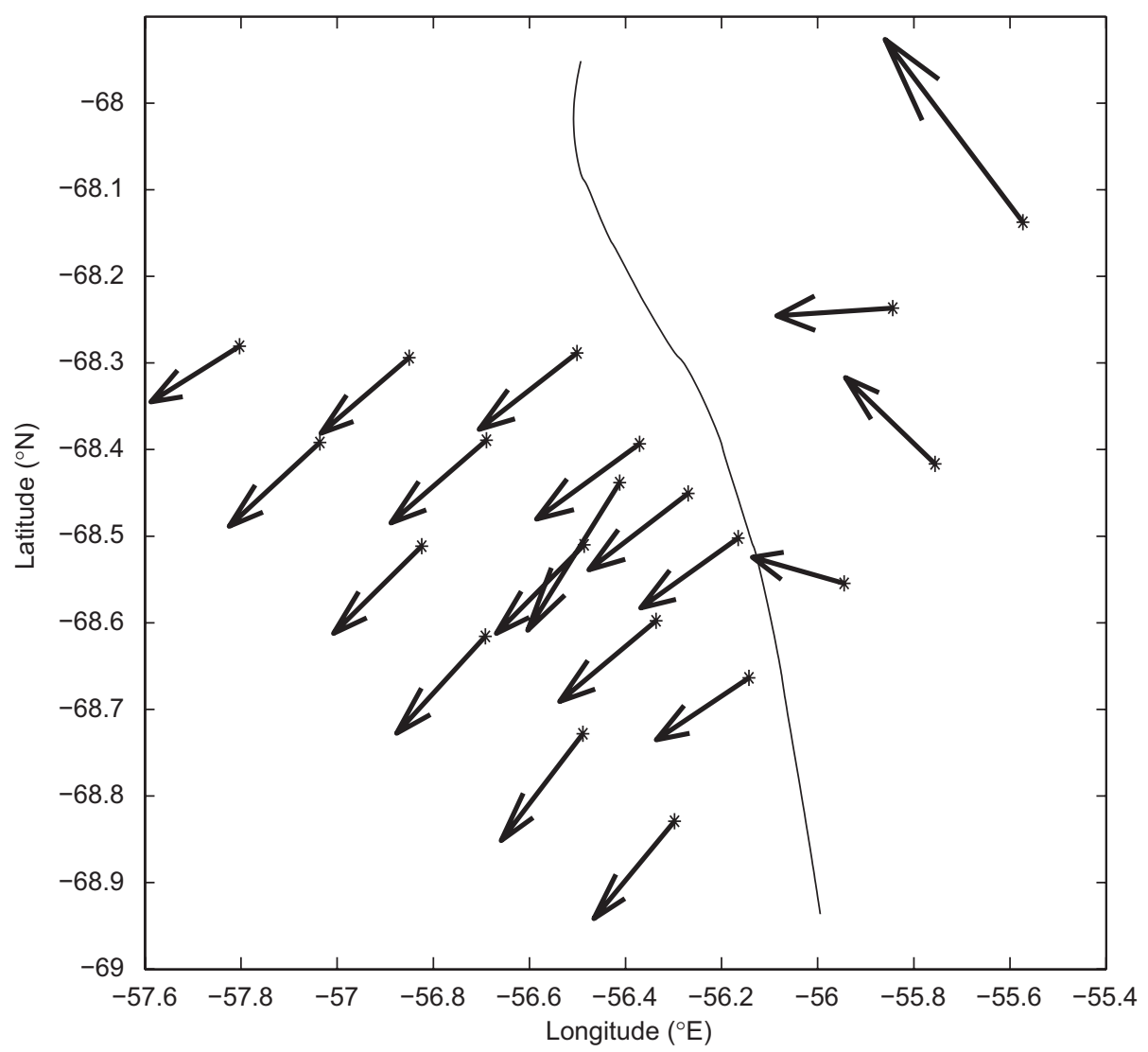

Fig. 12. Mean directional sea-ice translation (black arrows) for the ISPOL array averaged over the common ISPOL interval. The shear zone through the $I S P O L$ array is also shown (solid line). Stars show buoy deployment locations. 
(to the southwest) for sea ice in the western Weddell Sea, but also indicates a clockwise rotation of the ice-motion vectors in the northeastern part of the ISPOL array relative to other $I S P O L$ sites. To the west of this shear line net differential motion over the ISPOL interval was relatively small, whereas along the eastern edge of the array, net translation rotates from southwestward at the southernmost site W to northwestward at site F. The magnitude of translation is greatest for site F.
The complete analysis of the sea-ice deformation across all ISPOL sub-arrays and length scales is currently underway. Here we present an overview of the analysis of the ice deformation during ISPOL by selecting five triangular arrays: The outermost $I S P O L$ array (sites A, F and $\mathrm{W}$ ), an array near the centre of the ISPOL array (sites $\mathrm{O}, \mathrm{P}$ and $\mathrm{S}$ ), and one array each at the outer corners of the $I S P O L$ array (sites $\mathrm{A}, \mathrm{C}$ and $\mathrm{N}$; sites $\mathrm{F}, \mathrm{J}$ and $\mathrm{Q}$; and sites $\mathrm{R}, \mathrm{T}$ and $\mathrm{W})$. The scales of these arrays differ by two
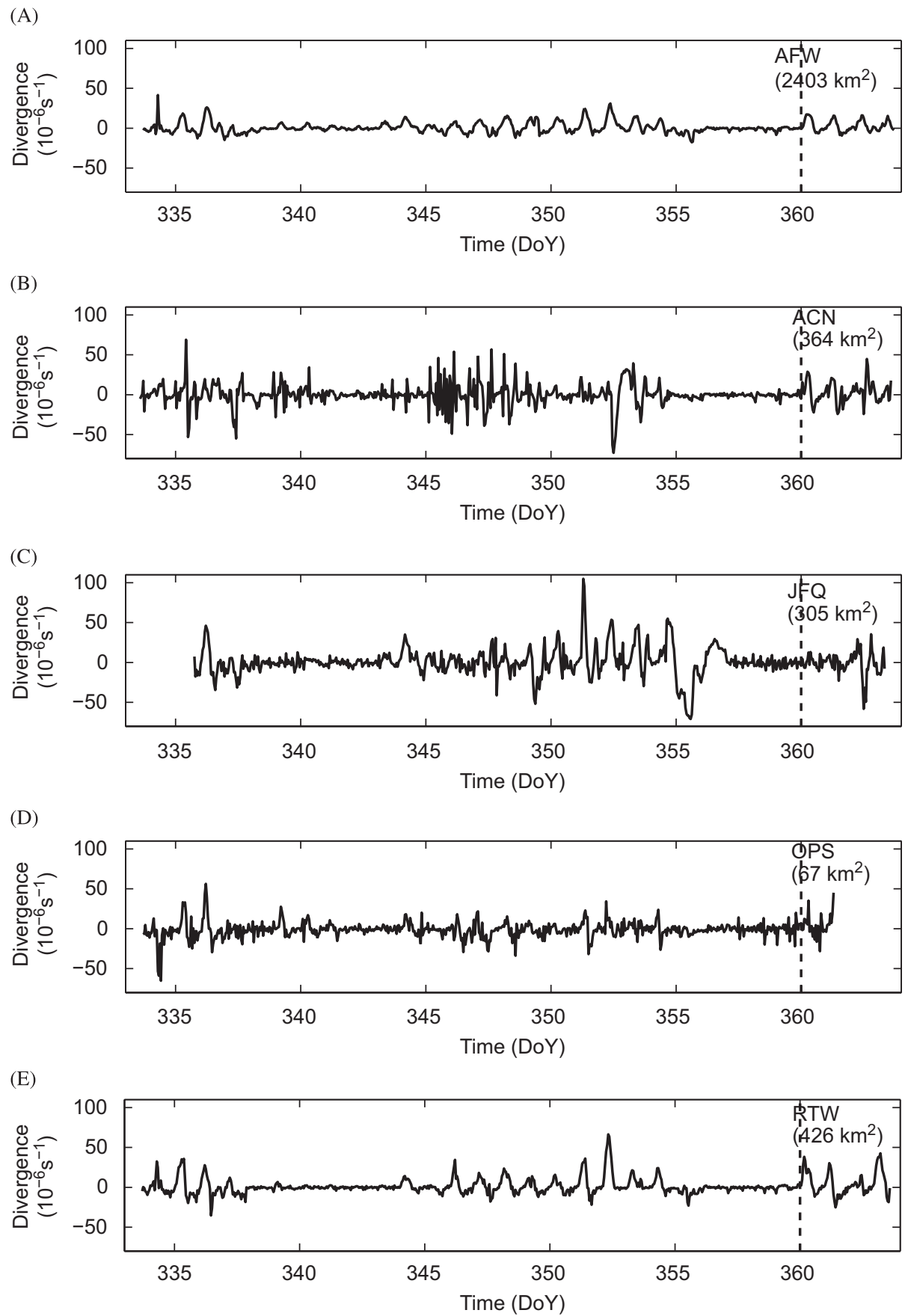

Fig. 13. Time series of the divergence for (A) the outer most triangle (Sites A, F, and W); (B) the northwestern most array (Sites A, C, and N); (C) the northeastern most array (Sites J, F, and Q); (D) the central most array (Sites O, P, and S); and (E) the southern most array (Sites R, T, and W). The dashed black line at DoY 360 marks the breakup of the ISPOL floe. The mean area enclosed by each array is shown in brackets. 
orders of magnitude. The outermost array (sites A, F and W) enclosed $2000-3000 \mathrm{~km}^{2}$, the corner arrays enclosed several hundred $\mathrm{km}^{2}$, and the area within the central array varied between 60 and $80 \mathrm{~km}^{2}$. The largest array (sites $\mathrm{A}, \mathrm{F}$ and $\mathrm{W}$ ) resolves meso-scale processes and the smallest array can be considered to resolve local processes (on the order of $10 \mathrm{~km}$ ).

The magnitudes of DKPs (as shown for sea-ice divergence in Fig. 13) vary slightly for the five arrays discussed here. The highest divergence amplitudes are seen for the northeastern array, which encompasses the shear zone apparent in Fig. 12, followed by the northwestern array. Based on our analysis of the DKPs for five arrays during ISPOL we cannot identify a clear dependence of the deformation parameters on the spatial scale. This aspect will be further investigated by considering all possible subarrays within the ISPOL array to provide a statistical description of the relationship between spatial scale and magnitude of the DKPs.

The two quiescent intervals seen in the ISPOL drift (see Section 4) are marked by low amplitudes in the DKPs. During these intervals the area enclosed by each of the five

(A)

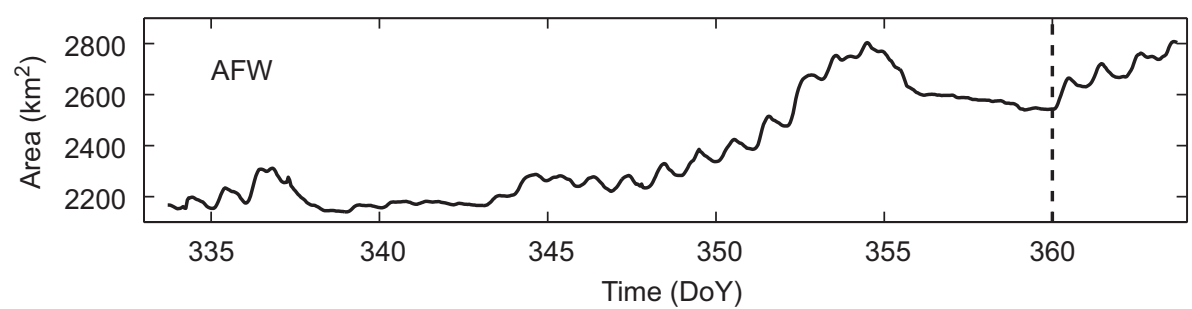

(B)

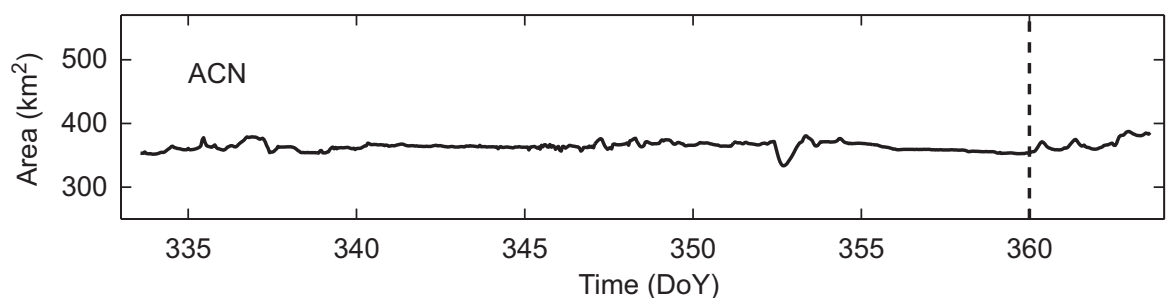

(C)

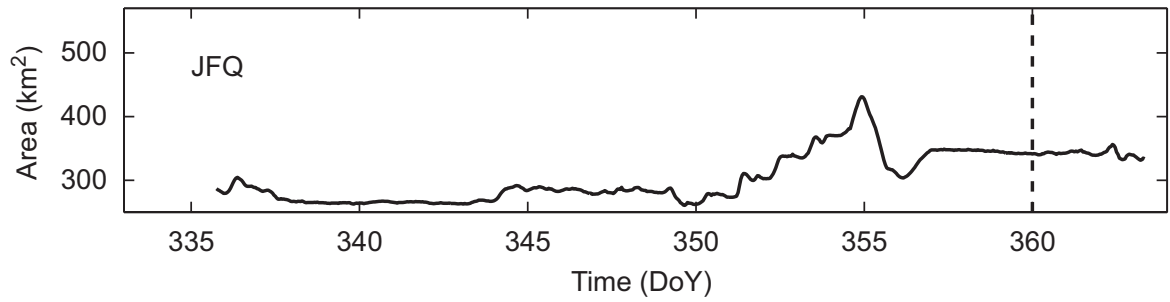

(D)

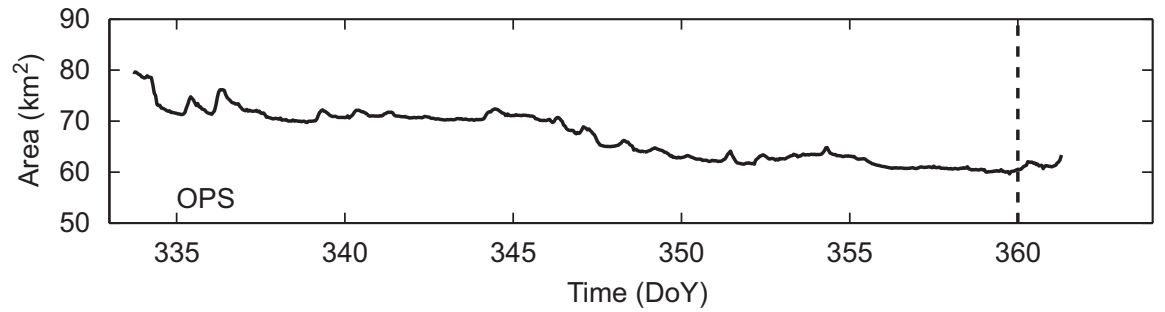

(E)

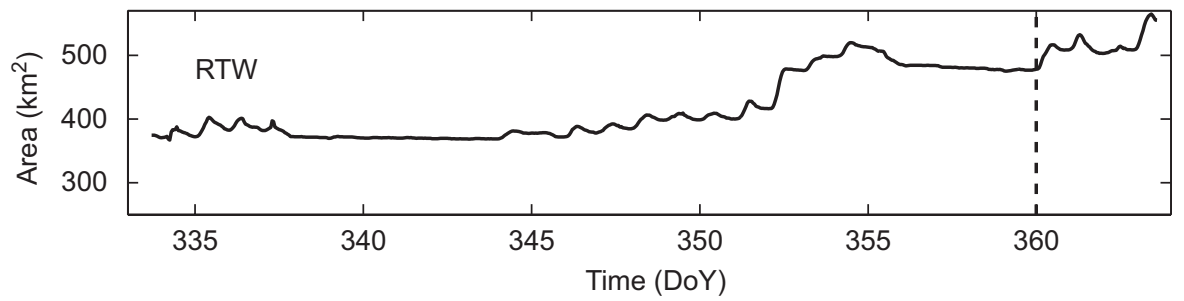

Fig. 14. Time series of the area enclosed within (A) the outer most triangle (Sites A, F, and W); (B) a northwestern array (Sites A, C, and N); (C) a northeastern array (Sites J, F, and Q); (D) the central most array (Sites O, P, and S); and (E) a southern array (Sites R, T, and W). 
arrays decreases slightly (Fig. 14). This quiescent behaviour cannot be explained by atmospheric conditions (see Section 4.4) nor is there any evidence in the AMSR-E data to suggest that increased ice concentration may have caused the ice drift to stagnate. Instead, coincident observations (McPhee, 2008) of the upper ocean indicate a reduction in the $\mathrm{K} 1$ and $\mathrm{M} 2$ tidal amplitudes during the two quiescent intervals. It should be noted here that the breakup of the ISPOL ice floe on DoY 360 coincided with increasing tidal amplitude and increasing southerly winds.

Following the events before and during the failure of the $I S P O L$ floe, initially vorticity (not shown here) increased from the southern arrays to the north. The ISPOL floe failure was followed by rapid strengthening normal deformation, shear deformation and finally divergence. Comparison with the atmospheric data from the R.V. Polarstern's weather station shows that the increase in vorticity coincided with a sharp reduction in surface pressure and a switch from northerly to southerly winds. As soon as wind speed increased, the amplitudes of normal and shear deformation increased too.

Averages of the DKPs (Table 1) are in the order of $10^{-7}$ or $10^{-8} \mathrm{~s}^{-1}$. Mean vorticity (shear) is the dominant process for three (two) out of the five arrays. The northeastern array (sites $\mathrm{J}, \mathrm{F}$ and $\mathrm{Q}$ ) shows the largest variance and shear deformation during ISPOL, while the southern array (sites R, T and $\mathrm{W}$ ) exhibits the largest divergence during ISPOL. Over the common ISPOL interval all but one array showed positive net divergence. The central array, being the smallest analysed here, showed a small net convergence $\left(0.098 \times 10^{-6} \mathrm{~s}^{-1}\right)$ during which its area was reduced by $15 \%$ (Fig. 14). The increase in array area for the remaining arrays varied from $3 \%$ for the northwestern array to $36 \%$ for the southern array. The high values of vorticity and also in shear deformation of the northeastern array is associated with the reshaping of the triangular array due to the local shear zone (see Fig. 12) that traverses through this array, and which separates the on-shelf and off-shelf sections of the ISPOL array.

Table 1

Temporal mean differential kinematic parameters and their variance for the five $I S P O L$ sub-arrays

\begin{tabular}{|c|c|c|c|c|c|}
\hline Array & Mean $(A)\left(\mathrm{km}^{2}\right)$ & $\begin{array}{l}\text { Mean }(D) \\
\text { Variance }(D)\end{array}$ & $\begin{array}{l}\text { Mean }(S) \\
\text { Variance }(S)\end{array}$ & $\begin{array}{l}\text { Mean }(N) \\
\text { Variance }(N)\end{array}$ & $\begin{array}{l}\text { Mean }(V) \\
\text { Variance }(V)\end{array}$ \\
\hline \multirow[t]{2}{*}{ AFW } & 2403 & 0.094 & 0.107 & -0.088 & 0.291 \\
\hline & & 0.452 & 0.571 & 0.609 & 0.024 \\
\hline \multirow[t]{2}{*}{ RTW } & 426 & 0.149 & 0.170 & -0.044 & 0.277 \\
\hline & & 1.290 & 1.220 & 0.981 & 0.052 \\
\hline \multirow[t]{2}{*}{$\mathrm{ACN}$} & 364 & 0.029 & -0.062 & -0.002 & 0.010 \\
\hline & & 1.844 & 2.055 & 2.820 & 0.028 \\
\hline \multirow[t]{2}{*}{ JFQ } & 305 & 0.072 & 0.354 & 0.087 & 0.858 \\
\hline & & 3.018 & 5.361 & 3.484 & 0.110 \\
\hline \multirow[t]{2}{*}{ OPS } & 67 & -0.098 & 0.164 & 0.011 & 0.142 \\
\hline & & 1.050 & 2.362 & 2.197 & 0.056 \\
\hline
\end{tabular}

Note that the arrays vary slightly in duration (see Fig. 13). Means are in units of $10^{-6} \mathrm{~s}^{-1}$; variances are in units of $10^{-10} \mathrm{~s}^{-2}$.

\subsection{Frequency analysis of ISPOL sea-ice deformation}

Similar to the analysis of the sea-ice velocities (Section 4.3), we have analysed the deformation parameters in the wavenumber-frequency domain. Fig. 15 shows the results of the frequency analysis for the ice divergence for the outer ISPOL array (sites A, F and $\mathrm{W}$ ) during the common ISPOL interval. The spectrum is dominated by a peak at the diurnal frequency; secondary peaks occur at both semidiurnal and low $(0.100-0.233$ cycles day $^{-1}$ ) frequencies. Similar results are found for the centre and southern arrays. On the other hand, the northwestern array exhibits equal signal strength in the diurnal and semidiurnal peaks, which dominate over a minor peak at low frequency. The spectrum of the northeastern array shows equal signal strength in the diurnal and low-frequency peaks and slightly less for the semidiurnal peak. The differences in these divergence spectra are unlikely to depend on the spatial scales of the arrays but rather are associated with the relative array position. For example, the northwestern array is the one furthest over the continental shelf and hence susceptible to tidal forcing.

The frequency analysis for the remaining DKPs supports the view that the parameters depend more on the array locale than on array size. We find that the spectra of shear deformation for three of our five ISPOL arrays show peaks at diurnal frequencies (for example for the outer array; Fig. 16), while the spectrum for the northwestern array shows peaks at semidiurnal frequencies, likely to be due to enhanced tidal forcing further on the continental shelf. At the same time for the northeastern array the spectrum peaks at diurnal as well as at low frequencies. Again, the differences between those two northern arrays are most likely due to their locations.

The total power density contained within the spectra varies over one order of magnitude. The power spectral density associated with the northeastern array is about twice that associated with the northwestern and southern arrays. The centre array contains slightly less power than those three arrays. The total power spectral density contained in the overall array is nearly a factor of 10 less than that in the northeastern array. Similar distributions are seen for the normal and shear deformation and also for vorticity. Our data are not sufficient to allow a conclusion on any scale dependency of the integrated power spectral density on array size.

\section{Discussion and conclusion}

Early summer (December 2004) sea-ice drift and deformation in the western Weddell Sea were observed using a total of 24 buoys, most of which were deployed within a meso-scale array. At deployment the buoys were arranged as an equilateral triangle (with approximately $76 \mathrm{~km}$ side length) in which smaller triangular arrays were embedded to allow the investigation of scale dependence, 


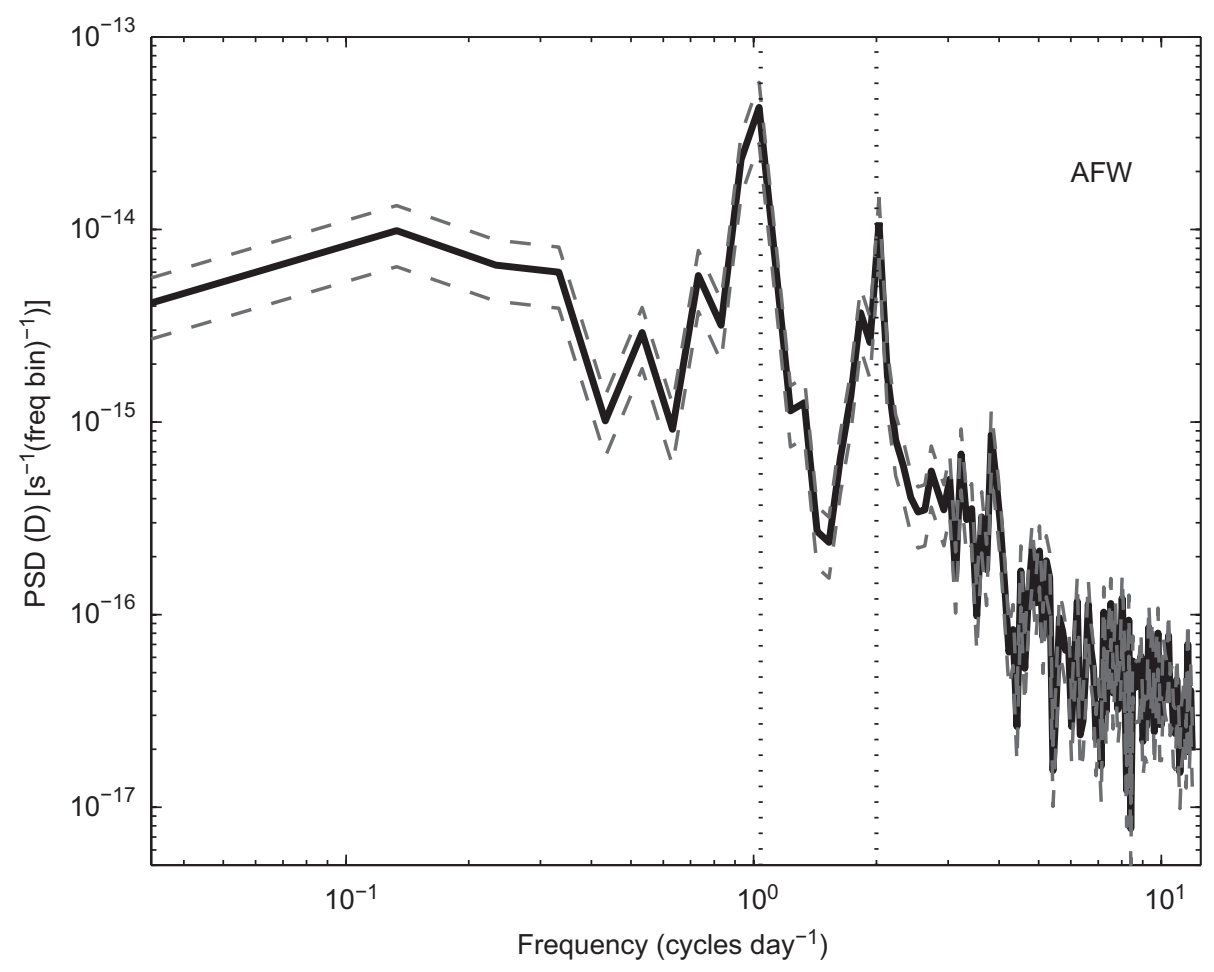

Fig. 15. Power spectral density (hi log-log presentation) for sea-ice divergence measured at the outer ISPOL array (sites A, F and W). The dashed black lines show the upper and lower error estimate. Vertical dotted lines indicate diurnal and semidiurnal.

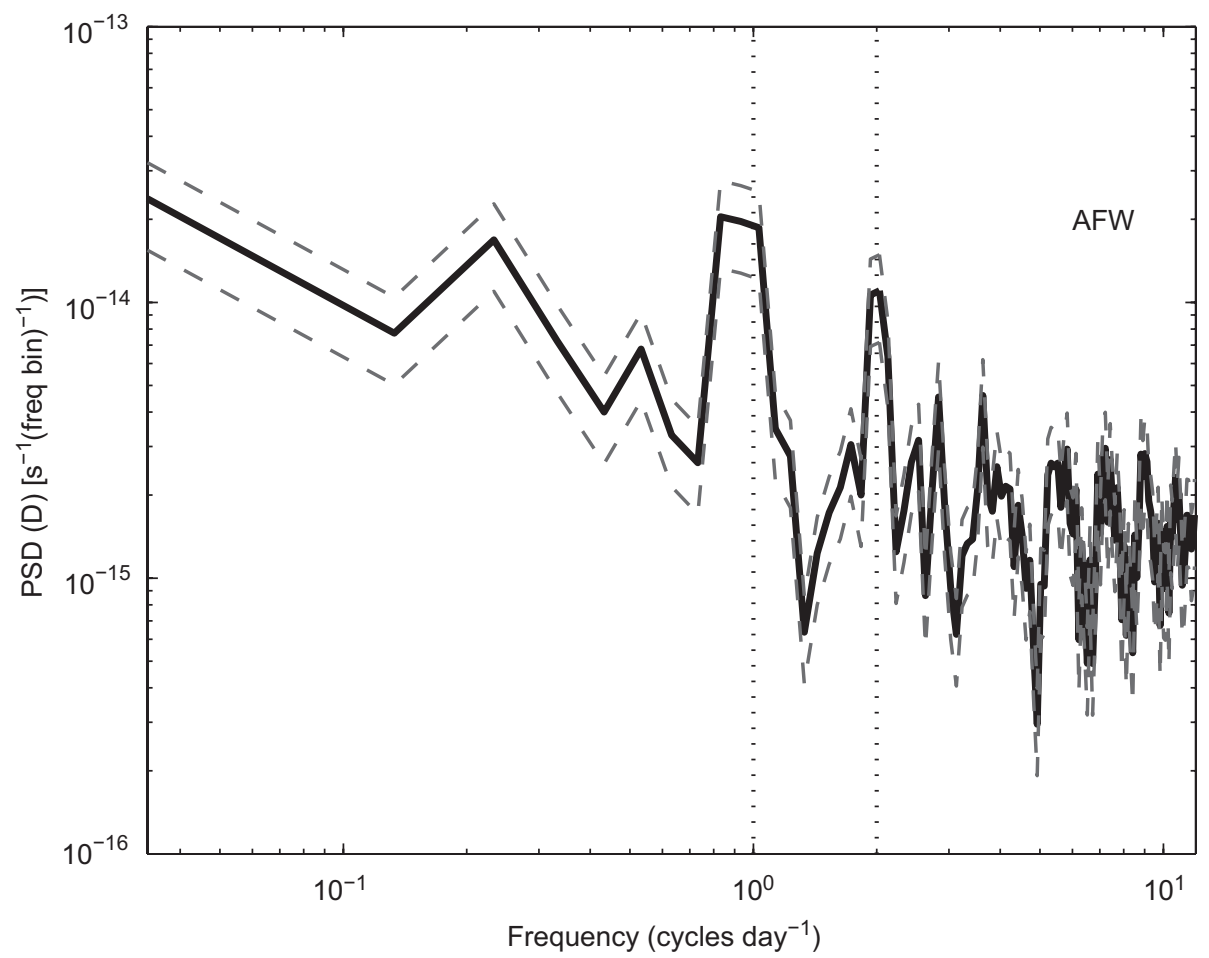

Fig. 16. Power spectral density (in log-log presentation) for sea-ice shear deformation measured at the outer ISPOL array (sites A, F and W). The dashed black lines show the upper and lower error estimate. Vertical dotted lines indicate diurnal and semidiurnal frequencies.

and to resolve ice drift and deformation at scales consistent with current modelling efforts. Ice drift characteristics in the northeastern part of the ISPOL array differed from that in the remainder of the array. This indicates that the $I S P O L$ array was deployed across a shear zone. During the common 26-day interval of the ISPOL buoys, zonal ice 
drift exceeded the meridional drift by a factor of 3. The meridional velocity component dominated the velocity variance. Meridional velocities decorrelated at separation scales of $60 \mathrm{~km}$, while zonal velocities did not decorrelate anywhere within the separation scales attained during ISPOL. The separation scale derived here is significantly less than the $360-540 \mathrm{~km}$ identified from the Winter Weddell Sea Project (Kottmeier and Sellmann, 1996). It is likely that under summer conditions, such as during $I S P O L$, local bathymetry is significantly more effective in steering the sea-ice drift, and hence giving rise to a directional dependence in the sea-ice drift.

The mean ratio of sea-ice velocity to wind velocity was small $(1.6 \%)$ during ISPOL and is comparable with the ones obtained during ISW-1. ISPOL sea-ice velocities themselves were within the same order of magnitude as during ISW-1. During ISPOL only a moderate correlation exists between ice drift and wind velocity. This is also reflected in the results of the frequency analysis, where we find peaks in power spectral density around 1 and 2 cycles day ${ }^{-1}$, with less power present at low frequencies. On the other hand, the frequency spectrum derived from the ISPOL wind velocities shows a red spectrum with little power spectral density at higher frequencies. Our data suggest that this difference in maxima in the power spectral densities is likely to be associated with (semidiurnal) tidal forcing, rather than due to an energy cascade towards semidiurnal frequencies.

An east-west gradient in power spectral density at diurnal and low frequency has been identified for both horizontal components of the sea-ice velocity. The peak amplitude in the semidiurnal power varied along the north-south axis of the array, and does not appear to be a function of ocean depth. Spectra of the rotary components were used to distinguish between various high-frequency forcings: sea-ice velocity at most sites appears to be dominated by oceanic tidal forcing, with atmospheric forcing and inertial response being secondary. However, in the northeastern part of the ISPOL array, off the continental shelf, the tidal forcing and inertial response combine to form the major driving forces for the sea-ice velocity.

We investigated the deformation of the ISPOL array and four sub-arrays. The differential kinematic parameters varied for the different arrays. During the ISPOL interval net divergence was driven by the southern array, but the northern sub-arrays exhibited the largest divergence amplitude. Quiescent intervals in ice drift and deformation do not correlate well with atmospheric forcing. Instead they seem to allow for a buildup of internal ice pressure, which may be eased during a release of stress when ice floes break up, as evidenced on the ISPOL floe itself toward the end of the experiment. Temporal changes in the distribution of floe size and floe numbers at transect lines along the $I S P O L$ array agree with this interpretation. Steer et al. (2008) found a shift from large ice floes to smaller floes during the $I S P O L$ interval, which is likely to be associated with the fracturing of larger ice floes, which then collapse along ridge lines.

For the spatial scales discussed here, neither ice motion nor ice divergence derived from the ISPOL array appear to depend on the spatial scale. Instead, spatial variability is largely due to bathymetric effects. In any case, caution must be exercised before generalising our findings, due to the shortness of our time series.

\section{Acknowledgements}

M.G. McPhee (McPhee Res. Company, USA) is thanked for discussions on high-frequency forcing of sea ice, and R.A. Robertson (ADFA, Australia) for her information on the ocean tides in the region of interest. Early input in project planning from V.I. Lytle (WCRP/ SCAR CliC Internat. Project Office, Norway) is acknowledged. A. Tivy, C. Hoffman and S. Willmes are thanked for their assistance with buoy deployments. M. Spindler (Univ. Kiel, Germany; ISPOL Chief Scientist), the helicopter crew and the R.V. Polarstern's captain and crew are thanked for their support. AWI is acknowledged for providing the opportunity to conduct this buoy experiment as part of ISPOL. J.L. Innis (AAD, Australia), J.L. Lieser and W.F. Budd (both ACE CRC, Australia) are thanked for their helpful comments on the manuscript, as are C.A. Geiger (Univ. Delaware, USA) and an anonymous reviewer. Some of our figures were compiled with GMT public domain software (Wessel and Smith, 1995). $A M S R-E$ sea-ice concentrations reported here are courtesy of the National Snow and Ice Data Center (USA).

Support for this project came from the Australian Antarctic Science Scheme (Grants \#742, \#2559 and \#2678); from IARC/JAMSTEC, from the Finnish Antarctic Research Programme (FINNARP). This work was also supported by the Australian Government's Cooperative Research Centres Programme through the Antarctic Climate and Ecosystems Cooperative Research Centre.

\section{Appendix A. Buoy types and accuracies}

Buoys supplied by the four partners differed in type and also in number and type of sensors they carried, which reflected the primary interest of the partner institutes. Two AAD buoys were ice beacons from MetOcean, while the other five AAD buoys were EZ ice markers from Clearwater. The three AWI buoys were sea-ice buoys by Denk Manufaktur. The three FIMR buoys were MetOcean ice beacons. Five IARC buoys were Oceanic Measurements' Model 406, while the other IARC buoys were custom made.

All buoys carried GPS receivers to determine their position. The MetOcean and Clearwater buoys used Jupiter GPS Engines with a horizontal accuracy of better than $20 \mathrm{~m}$ (at the $90 \%$ confidence level). The buoys from Denk Manufaktur used Trimble's Lassen-SQ, with a horizontal accuracy of better than $9 \mathrm{~m}(90 \%)$. All IARC 
Table A1

Component and total horizontal ( $\triangle$ hor) position accuracy for ISPOL buoys as compared to GPS position of the R.V. Polarstern for data obtained during pre-deployment sensor intercalibration

\begin{tabular}{|c|c|c|c|c|c|c|}
\hline Platform & GPS type & Sampling frequency & Transmissions & $\Delta x(\mathrm{~m})$ & $\Delta y(\mathrm{~m})$ & $\Delta$ hor $(\mathrm{m})$ \\
\hline 18848 (R) & JGE & $30 \mathrm{~min}$ & 20 & 23.7 & 20.6 & 31.4 \\
\hline $19020(\mathrm{U})$ & JGE & $30 \mathrm{~min}$ & 21 & 18.4 & 20.2 & 27.3 \\
\hline $19021(\mathrm{~V})$ & JGE & $30 \mathrm{~min}$ & 22 & 18.8 & 26.6 & 32.5 \\
\hline $19035(\mathrm{~T})$ & JGE & $30 \mathrm{~min}$ & 18 & 19.4 & 12.1 & 22.9 \\
\hline 19228 (S) & JGE & $30 \mathrm{~min}$ & 20 & 22.6 & 12.9 & 26.0 \\
\hline $20139(\mathrm{~W})$ & JGE & $30 \mathrm{~min}$ & 18 & 30.8 & 15.8 & 34.6 \\
\hline $20141(\mathrm{~F})$ & JGE & $30 \mathrm{~min}$ & 23 & 26.2 & 73.6 & 78.1 \\
\hline $8064(\mathrm{C})$ & TL-SQ & $60 \mathrm{~min}$ & 10 & 79.3 & 90.5 & 120.4 \\
\hline $9803(\mathrm{H})$ & TL-SQ & $60 \mathrm{~min}$ & 12 & 54.5 & 63.6 & 83.8 \\
\hline 14955 (D) & TL-SQ & $60 \mathrm{~min}$ & 9 & 93.9 & 128.4 & 159.1 \\
\hline $1154(\mathrm{~A})$ & JGE & $60 \mathrm{~min}$ & 15 & 195.9 & 212.8 & 289.2 \\
\hline $52292(\mathrm{Y})$ & JGE & $60 \mathrm{~min}$ & 30 & 56.7 & 23.9 & 61.5 \\
\hline $5892(\mathrm{X})$ & $\mathrm{JG}$ & $60 \mathrm{~min}$ & 12 & 17.7 & 13.7 & 22.4 \\
\hline $53536(\mathrm{Q})$ & G16N & $10 \mathrm{~min}$ & 80 & 16.4 & 16.4 & 23.2 \\
\hline $53537(\mathrm{E})$ & G16N & $10 \mathrm{~min}$ & 71 & 11.5 & 11.5 & 16.3 \\
\hline $53538(\mathrm{G})$ & G16N & $10 \mathrm{~min}$ & 80 & 14.0 & 14.0 & 19.8 \\
\hline 53539 (B) & G16N & $10 \mathrm{~min}$ & 63 & 10.8 & 13.3 & 17.1 \\
\hline $53541(\mathrm{~N})$ & G16N & $10 \mathrm{~min}$ & 85 & 14.7 & 2.7 & 15.0 \\
\hline (M) & G16N & $10 \mathrm{~s}$ & 36 & 31.7 & 21.1 & 38.1 \\
\hline (O) & G16N & $10 \mathrm{~s}$ & 12 & 11.6 & 20.0 & 23.1 \\
\hline (P) & G16N & $10 \mathrm{~s}$ & 36 & 26.1 & 19.3 & 32.5 \\
\hline
\end{tabular}

GPS receiver models are Jupiter GPS (JG), Jupiter GPS Engine (JGE), Trimble's Lassen-SQ (TL-SQ) and Garmin's 16N (G16N). Note that three IARC buoys did not have a Argos transmitter, hence only their ISPOL site ID is shown here.

buoys used Garmin's $16 \mathrm{~N}$, with a horizontal accuracy of better than $100 \mathrm{~m}(90 \%)$.

The horizontal accuracies of the various GPS units were tested prior their deployment. All ISPOL drifting sea-ice buoys were positioned on a single sea-ice floe adjacent to the R.V. Polarstern with their positioning devices and meteorological sensors activated for approximately $18 \mathrm{~h}$. This was primarily motivated by the need to calibrate the buoy's air pressure and temperature sensors. For the calibration the buoys were placed within an area of about $6 \times 3 \mathrm{~m}$. Where available these data have been used to compare the positional accuracy between the buoys (Table A1; see Heil et al. (2005) for details).

Different processing routines were required for data from each type of buoy. First erroneous data points were removed from the raw position data (and any auxiliary data). The quality-checked data were then projected on a equi-temporal grid (1 hourly) with a common time base a weighted polynomial interpolator (i.e., Scargle, 1982; Heil et al., 2001). This data transformation ensured that the inherent high-frequency energy distribution of the sea-ice motion was retained. Spectral analysis of the derived 1 hourly time series yields a Nyquist frequency of 12 cycles day ${ }^{-1}$.

\section{References}

Budd, W.F., 1986. The southern hemisphere circulation of atmosphere, ocean and sea ice. In: Volume to the Second International Conference on Southern Hemisphere Meteorology, December 1986. American Meteorological Society, Boston, pp. 101-106.
Crane, D., Wadhams, P., 1996. Sea-ice motion in the Weddell Sea from drifting-buoy and AVHRR data. Journal of Glaciology 42, 249-254.

Deacon, G.E.R., 1984. The Antarctic Circumsolar Ocean. Cambridge University Press, Cambridge, 180pp.

Geiger, C.A., Drinkwater, M.D., 2005. Coincident buoy- and SARderived surface fluxes in the western Weddell Sea during Ice Station Weddell 1992. Journal of Geophysical Research 110 (C04002).

Geiger, C.A., Ackley, S.F., Hibler III, W.D., 1998a. Sea ice drift and deformation processes in the western Weddell Sea. In: Jeffries, M.O. (Ed.), Antarctic Sea Ice Physical Processes, Interactions and Variability, Antarctic Research Series, 74. AGU, Washington, DC, pp. 141-160.

Geiger, C.A., Hibler III, W.D., Ackley, S.F., 1998b. Large-scale sea ice drift and deformation: comparison between models and observations in the western Weddell Sea during 1992. Journal of Geophysical Research 103, 21,893-21,913.

Gordon, A.L., Ice Station Weddell Group of Principal Investigators and Chief Scientists. 1993. Weddell Sea exploration from Ice Station. Eos Transactions, AGU 74, 121 and 124-126.

Heil, P., Allison, I., 1999. The pattern and variability of Antarctic sea ice drift in the Indian and Western Pacific sectors. Journal of Geophysical Research 104, 15,789-15,802.

Heil, P., Fowler, C.W., Maslanik, J., Emery, W.J., Allison, I., 2001. A comparison of East Antarctic sea-ice motion derived using drifting buoys and remote sensing. Annals of Glaciology 33, 139-144.

Heil, P., Worby, A.P., Hutchings, J.K., Launiainen, J., Johansson, M., Haas, C., Hibler III, W.D., 2005. Ice Station POLarstern [ISPOL]: drifting Buoy Data Report, ACE CRC Technical Report 1, 20pp, ISBN:1-921197-00-5.

Hellmer, H.H., Haas, C., Dieckmann, G.S., Schröder, M., 2006. Sea ice feedbacks observed in western Weddell Sea. Eos Transacctions, AGU 87 (18), 173.

Hellmer, H.H., Schröder, M., Haas, C., Dieckman, G.S., Spindler, M., 2008. The ISPOL drift experiment. Deep-Sea Research II, this issue [doi:10.1016/j.dsr2.2008.01.001]. 
Hibler III, W.D., Schulson, E., 1997. On modeling sea-ice fracture and flow in numerical investigations of climate. Annals of Glaciology 25, $26-32$.

Hibler III, W.D., Schulson, E.M., 2000. On modeling the anisotropic failure and flow of flawed sea ice. Journal of Geophysical Research $105,17,105-17,120$.

Jenkins, W.M., Watts, D.G., 1969. Spectral Analysis and its Applications. Holden-Day, Cambridge, 525pp.

Jones, D.A., Simmonds, I., 1993. A climatology of Southern Hemisphere extratropical cyclones. Climatic Dynamics 9, 131-145.

Kirwan Jr., A.D., 1975. Oceanic velocity gradients. Journal of Physical Oceanography 5, 729-735.

Kottmeier, C., Sellmann, L., 1996. Atmospheric and oceanic forcing of Weddell Sea ice motion. Journal of Geophysical Research 101, 20,809-20,824.

Kottmeier, C., Olf, J., Frieden, W., Roth, R., 1992. Wind forcing and ice motion in the Weddell Sea region. Journal of Geophysical Research 97, 20,373-20,383.

Lemke, R., 1994. Die Expedition ANTARKTIS X/4 mit FS Polarstern 1992. Reports on Polar and Marine Research, AWI, Germany, 140pp.

Little, R.J.A., Rubin, D.B., 1987. Statistical analysis with missing data. Wiley Series in Probability and Mathematical Statistics, 278pp.

Martinson, D.G., Wamser, C., 1990. Ice drift and momentum exchange in winter Antarctic pack ice. Journal of Geophysical Research 95, $1741-1755$.

Massom, R.A., 1992. Observing the advection of sea ice in the Weddell Sea using buoy and satellite passive microwave data. Journal of Geophysical Research 97, 15,559-15,572.

McPhee, M.G., 2008. Physics of early summer ice/ocean exchanges in the western Weddell Sea during ISPOL. Deep-Sea Research II, this issue [doi:10.1016/j.dsr2.2007.12.022].

McPhee, M.G., Ackley, S.F., Guest, P., Huber, B.A., Martinson, D.G., Morison, J.H., Muench, R.D., Padman, L., Stanton, T.P., 1996. The Antartic zone flux experiment. Bulletin of American Meteorological Society $77,1221-1232$.

Molinari, R., Kirwan, A.D., 1975. Calculations of differential kinematic properties from Langragian observations in the western Caribbean Sea. Journal of Physical Oceanography 5, 483-491.
Press, W.H., Flannery, B.P., Teukosky, S.A., Vetterling, W.T., 1990. Numerical Recipes-The Art of Scientific Computing. Cambridge University Press, Cambridge, 702pp.

Robertson, R.A., Padman, L., Egbert, G.D., 1998. Tides in the Weddell Sea. In: Jacobs, S.S., Weiss, R.F. (Eds.), Ocean, Ice, and Atmosphere: Interactions at the Antarctic Continental Margin. Antarctic Research Series, vol. 75. American Geophysical Union, pp. 341-369.

Rowe, M.A., Sear, C.B., Morrison, S.J., Wadhams, P., Limbert, D.W.S., Crane, D.R., 1989. Periodic motions in Weddell sea pack ice. Annals of Glaciology 12, 145-151.

Scargle, J.D., 1982. Studies in astronomical time series analysis. II. Statistical aspects of spectral analysis of unevenly spaced data. Astrophysical Journal 263, 835-853.

Steer, A., Worby, A.P., Heil, P., 2008. Observed changes in sea ice floe size distribution during early summer in the western Weddell Sea. DeepSea Research II, this issue [doi:10.1016/j.dsr2.2007.12.016].

Thorndike, A.S., 1986. Kinematic of sea ice. In: Unter-steiner, N. (Ed.), The Geophysics of Sea Ice, vol. 146. NATO ASI Series B, New York, pp. $489-548$.

Thorndike, A.S., Colony, R., 1982. Sea-ice motion in response to geostrophic winds. Journal of Geophysical Research 87, 5842-5852.

Uotila, J., Vihma, T., Launiainen, J., 2000. Response of the Weddell Sea pack ice to wind forcing. Journal of Geophysical Research 105, $1135-1151$.

Vihma, T., Launiainen, J., 1993. Ice drift in the Weddell Sea in 1990-1991 as tracked by a satellite buoy. Journal of Geophysical Research 98, $14,471-14,485$.

Vihma, T., Launiainen, J., Uotila, J., 1996. Weddell Sea ice drift: Kinematics and wind forcing. Journal of Geophysical Research 101, 18279-18296.

Wadhams, P., Sear, C.B., Crane, D.R., Rowe, M.A., Morrison, S.J., Libert, D.W.S., 1989. Basin-scale ice motion and deformation in the Weddell Sea during winter. Annals of Glaciology 12, 178-186.

Wessel, P., Smith, H.F., 1995. New version of the generic mapping tool released. Eos Transactions, AGU 76 (33), 329.

Wunsch, C., 1975. Internal tides in the ocean. Reviews of Geophysics and Space Physics 13, 167-182. 